8-1-1975

\title{
A Q-Methodological Study of the Kubler-Ross Stage Theory
}

Anne M. Metzger

How does access to this work benefit you? Let us know!

Follow this and additional works at: https://commons.und.edu/theses

\section{Recommended Citation}

Metzger, Anne M., "A Q-Methodological Study of the Kubler-Ross Stage Theory" (1975). Theses and Dissertations. 2810.

https://commons.und.edu/theses/2810

This Thesis is brought to you for free and open access by the Theses, Dissertations, and Senior Projects at UND Scholarly Commons. It has been accepted for inclusion in Theses and Dissertations by an authorized administrator of UND Scholarly Commons. For more information, please contact und.commons@library.und.edu. 
A Q-METHODOLOGICAL STUDY OF THE KUBLER-ROSS STAGE THEORY

$$
\text { by }
$$

Anne M. Metzger

Bachelor of Arts, Muskingum College, 1972

\section{A Thesis}

Submitted to the Graduate Faculty of the

University of North Dakota

in partial fulfillment of the requirements

for the degree of

Master of Arts

Grand Forks, North Dakota 
Permission

Title A Q-METHODOLOGICAL STUDY OF THE KUBLER-ROSS STAGE THEORY

Department Psychology

Degree ___ Master of Arts

In presenting this thesis in partial fulfillment of the requirements for a graduate degree from the University of North Dakota, I agree that the Library of this University shall make it freely available for inspection. I further agree that permission for extensive copying for scholarly purposes may be granted by the professor who supervised my thesis work or, in his absence, by the Chairman of the Department or the Dean of the Graduate School. It is understood that any copying or publication or other use of this thesis or part thereof for financial gain shall not be allowed without my written permission. It is also understood that due recognition shall be given to me and to the University of North Dakota in any scholarly use which may be made of any material in my thesis.

signature Ene motzen Date Gulg $18,19>5$ 


\section{ACKNOWLEDGEMENTS}

The most important contribution to this study was made by the husbands and wives who served as subjects and by the doctor who referred them to me. Their willingness to discuss their experiences with serious illness not only made this résearch possible, but also added to my conviction that this area must be studied.

I would like to thank Beulah Hedahl, who chaired the committee which directed this research, for her willingness to become involved in this project and her assistance in ensuring its completion. Michael Rohrbaugh deserves special thanks for his assistance in the original formulation of the problem and his continued accessibility as a source of encouragement and morale. Thanks also goes to Denny Murray for his active participation on the committee, despite his late addition. A special note goes to Nancy Huntsman for her service on the committee until her departure from campus.

Finally, I would like to thank my husband, Rich, for his continuing patience and encouragement as a friend and his critical and editorial assistance as a colleague. 
ACKNOWLEDGEMENTS ....................... iv

LIST OF TABLES ........................... vii

ABSTRACT .............................. viii

\section{Chapter}

I. INTRODUCTION ..................... 1

II. REVIEW OF THE LITERATURE ............ 8

The Kubler-Ross Stage Theory

The Concept of Death Anxiety

Empirical Research Focusing on

Psychological Variables in

the Terminally IIl

Studies of the Interaction of

Psychological and Physiological

Variables in the Terminally Ill

Other Paradigms for Investigating

the Terminally IIl

III. METHOD . . . . . . . . . . . . . . . .

Subjects

Development of the Q-sort Instrument

Procedure of Data Collection

Procedure for Data Analysis

IV. RESULTS .................. .

Evaluation of the Consistency of Q-sort Descriptions

Q-factor Analytic Results

Summary of Factor Analytic Results

Adequacy of the Kubler-Ross Item

Categories 
Chapter

V. DISCUSSION .......................... 49

Implications for the Kubler-Ross

Stage Theory

Implications for the Use of Q-methodology

Summary

APPENDIX A: JUDGE'S RATING FORM FOR ORIGINAL ITEM POOL $\ldots . .57$

APPENDIX B: THIRTY-SIX ITEM Q-SORT STATEMENTS . . . . . . 62

APPENDIX C: SUBJECT INSTRUCTIONS FOR PERFORMING Q-SORTS . . . 67

APPENDIX D: Q-SORT RANKINGS .............. 70

APPENDIX E: Q-SORT CORRELATION MATRICES . . . . . . . 73

APPENDIX F: UNROTATED FACTOR LOADINGS . . . . . . . . 76

APPENDIX G: NORMALIZED FACTOR SCORES AND Q-SORT ARRAYS . . . 78

LIST OF REFERENCES . . . . . . . . . . . . 86 


\section{LIST OF TABLES}

1. Judge's Stage Ratings Obtained

on Original Item Pool ...............

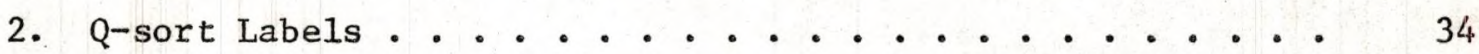

3. Intra-subject and Inter-subject

Correlations Cases A and B . . . . . . . 37

4. Rotated Factor Loadings: Case A . . . . . . . 40

5. Rotated Factor Loadings: Case B .......... 42

6. Category Variance for Each Q-sort . . . . . . . 48

7. Case A Q-sorts ................... 71

8. Case B Q-sorts ................... 72

9. Q-sort Correlation Matrix: Case A . . . . . . 74

10. Q-sort Correlation Matrix: Case B . . . . . . 75

11. Unrotated Factor Loadings: Case A . . . . . . . 77

12. Unrotated Factor Loadings: Case B . . . . . . 77 
ABSTRACT

Kubler-Ross (1969) identified a progression through stages of denial, anger, bargaining, depression, and finally acceptance as a completion of the dying process. These stages are encompassed by feelings of hope which extend throughout the course of illness. The present study was designed to investigate the correspondence between the stage changes hypothesized by the Kubler-Ross theory and the perception of the course of illness by seriously ill patients and their spouse. An additional focus of the study was an evaluation of Q-methodology as a research procedure with the terminally ill.

A thirty-six item structured Q-sort was administered on two occasions to two couples, in each of which the wife had a potentially terminal medical diagnosis. Subjects described the patient's perception of the illness at the present time and as it had been at four other times since the diagnosis. The Q-sorts of each couple were intercorrelated and submitted to Q-factor analysis.

The results supported the use of Q-methodology as a research procedure for investigations of terminal illness. The subjects experienced no difficulty in using the instrument and the Q-factor analysis produced factors which organized patient and spouse perceptions of the present and recalled times since the diagnosis of the illness. The implications for the validity of the Kubler-Ross theory were ambiguous. 
Factors which emerged did not reveal the Kubler-Ross structure in the Q-sort nor was there evidence of stages. Pervasive feelings of hope may have masked any evidence of Kubler-Ross stages, the recall methød may not have been accurate enough to reveal stages, the Kubler-Ross stages may be cyclical in these patients, or the theory may not be supported when further subjected to empirical validation.

Suggestions for further research regarding the presence of psychological stages in the dying process and the potential uses of Q-methodology were discussed. 


\section{CHAPTER I}

\section{INTRODUCTION}

The study of death has become an area of psychological investigation only during the past twenty years. Interest in this area of research has grown slowly; the social taboo against entering the field of death research has been compared to the Victorian taboo against consideration of sexual issues (Wahl, 1958). However, involvement has spread to the point where major universities have research centers exclusively devoted to studying the effects of death related events on whole societies as well as individual persons.

Death is a crisis situation, and psychologists are interested in the ways people behave under stress. One of the questions psychologists have approached is what happens to a person psychologically from the time he is diagnosed with a terminal illness until his death. A comprehensive attempt to describe the psychological process during the course of dying was made in Elisabeth Kubler-Ross's stage theory (1969). As a psychiatrist, Kubler-Ross worked with over 200 terminally $i 11$ hospitalized patients during a period of more than two years before publishing On Death and Dying as a summary of her experience. She cited no statistical support for her conclusions, but based them instead on repeated psychiatric interviews with her patients. 
The stage theory which she described is a series of coping mechanisms which are used during a terminal illness. Acknowledging that patients react differently depending upon their personality and style of living, she organized the dying process into a series of defenses which may be utilized to a greater or lesser extent as the patient's personality and interpersonal relationships demand. KublerRoss identified stages of denial, anger, bargaining, depression, and finally acceptance as a completion of the dying process. She also noted that a sense of hope pervades the entire progression toward death without any stage-1ike changes.

There have also been attempts to use empirical data to explain the dying process. All these researchers have investigated the terminally ill by analysis of group data, and all but one (Lieberman, 1965, 1966; Lieberman and Coplan, 1970) have also ignored the duration of the illness. In addition, several studies have considered the terminally ill at only one (Thomas and Weiner, 1974; Davies, Quinlan, McKegney and Kimbal1, 1973) or two (Achte and Vauhkonen, 1971) points in time, without regard for changes which might occur in a progressive manner. As a more extensive review of both the Kubler-Ross theory and the empirical research will indicate in Chapter II, previous studies of the terminally ill have disregarded the Kubler-Ross orientation toward the single individual and his ability to deal with dying as a process occurring over a long period of time.

Although it has no empirical research base, the Kubler-Ross theory has been accepted as valia by a variety of health-related professionals including hospital chaplains, social workers, and nursing 
personnel. Due to the acceptance of this theory, based solely on face validity, an attempt to establish empirical support was clearly warranted. The present study was designed to investigate the correspondence between the stage changes hypothesized by Kubler-Ross and the perception of the course of illness by seriously ill patients and one of their closest significant others; that is, do descriptions obtained from those directly affected by terminal illness suggest any stages paralleling those of the Kubler-Ross theory.

One of the problems in testing a hypothesis developed from the Kubler-Ross theory is that of finding an appropriate methodology that respects the individual patient's privacy and protects him from unnecessary emotional strain. In developing a procedure which would deal with this problem, it was decided to explore the use of Q-methodology as a means of analyzing the process of illness in a limited number of cases. Q-sorts have previously been used over a period of time to describe changes occurring in a dying patient's needs (Zinker and Fink, 1966). This approach was chosen for its ability to demonstrate both the feasibility of the technique and the probability that further research with more individuals in a longitudinal perspective would be fruitful. As Dukes (1965) has suggested, small n research may provide a valuable contribution by indicating specific approaches to an issue and suggesting directions for future research. The continued sensitivity of research with the terminally ill indicated the need for this type of exploratory investigation. By using a small $\mathrm{n}$ design and a collapsed time perspective, the research methodology could be evaluated 
with a minimal expenditure of time and emotional energy on the part of the patients.

The present study proposed to develop a structured Q-sort which would be used by both a terminally ill patient and the patient's spouse. The Q-sort would provide a means by which on the one hand the patient could describe his own experience, and on the other, the spouse could describe his perception of the patient's experience. Due to the exploratory nature of this investigation, the patient and spouse were asked to make their descriptions after the diagnosis had been known for some time. Thus, they were asked to remember their perceptions of the patient's experience at different points in time, as well as to describe their perceptions of the patient's present experience.

An important facet of the investigation involved the construction of a Q-sort instrument which subjects could use to describe a seriously ill patient. These perspectives could then be intercorrelated and factor analyzed to examine the pattern which emerged. The Q-sort instrument is a convenient measurement tool because the items can be used repeatedly by the same subject with a variety of instructional orientations. Stephenson's (1953) comprehensive presentation of Qmethodology stressed the appropriateness of Q-technique in providing structure for a variety of self-descriptions made under different instructiona1 sets.

A Q-sort is a series of descriptive statements which an individual is asked to rank, placing the statements in a given number of categories along some specified dimension, from "least" to "most," with a designated number of statements allowed in each category. One 
investigation of the terminally ill has already used a Q-sort methodology. Zinker and Fink (1966) taped open-ended interviews with a terminally ill woman over a five-month time period. Each interview was rated by two psychologists using a 60-item Q-sort structured upon Maslow's need hierarchy. The items were sorted twice by each rater for each interview, once to describe the subject by sorting the items from those most characteristic of her to those least characteristic of her and again by sorting the items from those needs most satisfied to those least satisfied.

Zinker and Fink's employment of Q-sorts seemed useful, but their particular Q-sort was not applicable because it was structured on a different theory. In a structured sample of Q-sort items the stimuli. which will be included are determined by the experimental design. Thus, a Q-sort was constructed to sample equally the Kubler-Ross stages, using Nunnally's (1967) directions for building a structured Q-sort. In the present study the items were based on written and recorded statements of terminally ill patients and phrased for use by laymen, rather than professionally worded for use by psychologists.

Q-technique has successfully been employed to trace therapeutic change over time by having the client describe both present perspectives of himself and retrospectively describe his childhood and adolescence (Nunnally, 1955). Third person raters have also successfully used Q-sorts to describe changes in a client's perception of his parents and therapist (Subotnik, 1966).

The present investigation used a modified case study design, focusing on the four individual members of two married couples, where 
one member of each couple had been given a potentially terminal medical diagnosis. Each couple as a unit was considered independently. Members of a couple were asked to use the Q-sort instrument to describe their present perception of what the patient had experienced, both at different points in time since the diagnosis and at the present.

Although an ideal test of the Kubler-Ross hypothesis would require that changes in patient's' experience be examined in a longitudinal study lasting from the diagnosis of illness to the time of death, the time investment required by such a study appeared unjustified without a prior investigation of methodology and procedures. In this exploratory evaluation of the potential of Q-methodology two approaches were used to examine the pattern of experience of both the patient and spouse. One approach compared two Q-sorts describing the patient's present experience made by the same individual at two different times. This comparison provided an indication of the consistency, or reliability, with which each subject could describe the same period of time. The second approach compared additional Q-sorts describing earlier points in time during the illness. Although these Q-sorts may not be an accurate description of the true sequence of experience, it is hoped that they might at least provide an indication of whether patients and spouses are aware of changes they have undergone, even though they may not be recalled in the Kubler-Ross order.

In summary, two couples were asked to use a structured Q-sort to describe their present perception of the terminally ill member of the couple (either themself or their spouse) at the current time and at several points during the period since the medical diagnosis had been 
made. These descriptions were then intercorrelated and factor analyzed for each couple. Answers to several questions were sought in the data analyses:

1. Would the individual subjects be able to provide reliable descriptions of the patient's experience, as indicated by their two present descriptions?

2. Would the Q-sorts of each couple correlate highly at each point in time described?

3. Would factor analysis indicate that a couple's Q-sorts at parallel points of time have significant loadings on the same factors?

4. Would factor loadings show systematic trends across the time line defined by the Q-sorts, reflecting the stages involved in facing terminal illness?

5. Would the factor scores of the Q-sort items provide factor labels resembling the Kubler-Ross stages?

6. Would a comparison of the total variance of each Q-sort and the variance of the items representing each stage indicate that the stage items were sorted together, and thus that the structure of the Q-sort was actually used by the subjects in making their descriptions? 


\section{CHAPTER II}

\section{REVIEW OF THE LITERATURE}

The lack of correspondence between Kubler-Ross's conceptualization of the dying process and the research orientation of empirical investigators has already been noted. The picture of this dicotomy will be enlarged by a more extensive description of the Kubler-Ross position, a brief note about the concept of death anxiety, and finally a description of representative empirical studies and their relationship to Kubler-Ross theory.

\section{The Kubler-Ross Stage Theory}

Kubler-Ross described the initial reaction to knowledge of having a terminal illness as temporary shock; this initial response is followed by the first defensive reaction which is denial and isolation. The patient says "No, not me, it can't be true." Denial is used by almost all patients with forms of partial denial frequently occurring again later in the course of illness. Kubler-Ross stressed that denial. is ". . a healthy way of dealing with the uncomfortable and painful situation with which some of these patients have to live for a long time... (It) allows the patient to collect himself and, with time, mobilize other, less radical defenses" (Kubler-Ross, 1969, p. 39). A1though denial is viewed as only the beginning stage of a long process, 
some patients may not be able to utilize other coping behaviors and continue to employ denial during their entire dying course.

Anger, rage, and resentment replace denial when it can no longer be maintained. This second stage represents the question "Why me?" The patient reacts to a constant confrontation with activities and experiences he may no longer have, as well as a decreasing amount of self control over his own life. Anger may be directed toward any person in the environment including doctors, nurses, family, friends, and God. Bargaining is the third stage of defense, but it is briefer and less visible to observers than the other stages. An attempt is made to negotiate some sort of agreement which may postpone the inevitable. The most frequently bargained for event is an extension of life, followed by a desire for time without pain or physical discomfort. "The bargaining is really an attempt to postpone; it has to include a prize offered 'for good behavior,' it also sets a self-imposed 'deadline,' and it includes an implicit promise that the patient will not ask for more if this one postponement is granted" (Kubler-Ross, 1969, pp. 83-84). A patient's bargaining often goes unperceived because it frequently takes the form of silent prayer or unspoken promise.

Eventually other coping mechanisms are no longer as necessary, and the dying patient begins to experience a sense of great loss, taking the form of depression. Kubler-Ross differentiated two distinct types of depression in the dying. One is a reactive depression in response to events which have already happened, perhaps a functional loss, an economic loss, or a role loss. This type of depression, as well as its accompanying guilt or shame, can be dealt with by understanding the 
patient and helping him build self-esteem. However, the other form of depression is a preparatory depression or anticipatory grief. "When the depression is a tool to prepare for the impending loss of all love objects, in order to facilitate the state of acceptance, then encouragements and reassurances are not as meaningful" (Kubler-Ross, 1969, p. 87). Kubler-Ross strongly supported this form of depression as a healthy expression of sorrow and explains that this anguish and anxiety must be worked through before the final stage may be reached.

If the patient is given the time and emotional permission to progress through the previous four stages he will eventually reach a stage of being neither depressed nor angry, which is almost void of feelings. This stage is an acceptance of one's own death and is presented as the desirable final stage.

We have found that those patients do best who have been encouraged to express their rage, to cry in preparatory grief, and to express their fears and fantasies to someone who can quietly sit and listen. We should be aware of the monumental task which is required to achieve this stage of acceptance, leading toward a gradual separation (decathexis) where there is no longer a two way communication (Kubler-Ross, 1969, p. 119).

If a stage of acceptance is attained, death is no longer viewed as a crisis and defense mechanisms are not necessary.

Another psychological response of the dying is hope, although Kubler-Ross did not consider it to be a psychological stage since it persists throughout the entire process of dying. Hope is seen as providing an important rationalization for suffering, a temporary denial, or a form of reward for enduring. Hope is necessary for the dying because it enables them to continue living. Problems relating to hope 
occur if other people convey hopelessness to a patient who still needs this support, or if a patient is ready for acceptance but others around him still cling to hope.

Dying, in Kubler-Ross's theory, is viewed as an ongoing process in which several phases or stages may be identified. An emphasis is placed on the quality of mental health in all the forms of coping, but special emphasis is placed on the desirability of reaching a stage of acceptance of one's own death. Her writing seems to indicate that all dying patients should pass through all these stages but that some patients are unable to accomplish this.

An additional factor which may influence a patient's progression through the stages is his interpersonal relationships. The stage theory is grounded in the importance of the interpersonal context in which the terminally ill is located. It is through other people's recognition of his need for defenses that the patient is able to make some progress toward acceptance. Thus his family's ability to perceive what he experiences assumes additional importance for the terminally ill. Kubler-Ross observed many instances where the progress toward acceptance was completed; perhaps this was due to her continued personal involvement with the patients, which in essence provided them with ongoing therapy.

In attempting to account for some of the interpersonal contexts which occur, Kubler-Ross made the assumption that there is both an individual and a societal denial of death which is based on a universal death anxiety. This death denial is the source of the problem which the healthy encounter in attempting to deal appropriately with the dying. 


\section{The Concept of. Death Anxiety}

The concept of a death anxiety is not unique to Kubler-Ross's theory, but has been a specific topic of further psychological investigation. Wahl (1958) and Feifel (1959) helped to initiate the current research in death anxiety and denial. Lester (1967) notes that psychological interest in death-related issues has 1 ed to two distinct areas of investigation. One line of research has focused upon exploration and measurement of the fear of death in society as a whole, while the other has centered on the study of the psychological state and managenent of the dying patient. Since the present investigation falls into this latter broad division of research interest, an extensive review of the literature on death anxiety will not be presented. Comprehensive reviews of this literature have been organized by Lester and also by Kastenbaum and Aisenberg (1972). They conclude that although the term "death anxiety" is widely used, there is little concensus regarding the origin of this fear or its meaning.

\section{Empirical Research Focusing on Psychological Variables in the Terminally I11}

The unique aspect of On Death and Dying is Kubler-Ross's conceptualization and labeling of specific phases of the dying process, and her observation that terminally ill patients will generally reveal a specific pattern of psychological response to this stress situation. While the Kubler-Ross theory is based on multiple case studies, other investigators have attempted to use quantitative methods to describe the dying process and the terminally ill. A variety of statistical 
approaches have been used including descriptive, correlational, and inferential methods.

In an early investigation of the dying, Cappon (1959) used a bedside interview approach to obtain data. There were 19 dying patients compared with 88 unmatched control patients who had other physical or psychiatric diagnoses. Without providing a clear presentation of his rating methods, a descriptive evaluation was given of emotional status, ego structure, ego defenses, motivation in dying, foreboding of death, and communications. Cappon concluded that there is no personality change in the process of dying, identifying no trends which would be conducive to a stage interpretation.

In an investigation which focused more on the dying patient's awareness of his diagnosis, Achte and Vauhkonen (1971) also discussed psychological symptoms in the dying. Their subjects were 100 persons under treatment for cancer who were assigned to one of four groups according to the spread of the disease. A psychiatric interview with each patient, his case records, and staff interviews were used to assess each patient's knowledge of the nature of his illness, and observations of psychological symptoms were recorded. Achte and Vauhkonen found more than half the patients were observed to display tenseness, depression, or anxiety. Aggressiveness and paranoid attitudes were also common reactions, while phobic, obsessive, or neurotic reactions were rare. At a two year follow-up a further comparison was made of two subgroups, those who were living at the time of the follow-up and those who had lived less than a year. The original data indicated that those who had died in a short length of time had tended to repress anxiety-evoking 
realities more actively, appeared to "cling to life" less, were significantly more depressed, were more passive and dependent, showed less self-esteem, displayed significantly more aggressiveness, and were more hopeless regarding the possibility for recovery.

These results cannot be interpreted in relation to the KublerRoss theory since the data were obtained at a single point in time and do not have the potential to 'reveal stage qualities. However, Achte and Vauhkonen did discuss denial, aggression, depression, and degree of hope as differentiating the subjects who died from those still surviving; these reactions are also components of the Kubler-Ross stages.

Thomas and Weiner (1974) compared groups of 25 critically ill hospitalized patients, 25 noncritically ill hospitalized patients, and 25 normal well controls. Two questionnaires and a comparison of eye blinks to neutral and disease related material were used as dependent measures. Hypotheses were that critically ill patients would demonstrate a higher purpose in life, that critically ill patients could be differentiated from other groups as to their expression of and desire for inclusion, control, and affection in interpersonal relationships, and that average frequency of eye blinks would be higher for critically ill patients when listening to disease related material. The researchers included the hypothesis concerning interpersonal relationships partially on the basis of Kubler-Ross's discussion of changes in interpersonal relationships during terminal illness.

Discriminate function analysis revealed that the critically ill group could be differentiated on the basis of having more purpose in life, increased need for affection and inclusion, decreased wanted 
control from others, and increased rate of eye blinks in response to disease-related material. Thomas and Weiner concluded that the critically ill can be considered a psychologically unique group. Since this investigation looked at patients from only one point in time, there is again, no opportunity to examine these results from a stage perspective. The authors did, however, discuss the possibility that increased purpose in life reflected a ". . preparation for death and a higher level of comfort with his value and accomplishments in life, somewhat similar to the 'fifth' and final stage of 'acceptance and inner peace' proposed by Kubler-Ross" (Thomas and Weiner, 1974, p. 277), indicating that they did not exclude the possibility of there being phases in the dying process. In another recent study, Carey (1974) also attempted to use a quantitative approach to the study of the emotional adjustment in the terminally ill. Seventy-four terminally ill patients who accepted counseling by one of eleven hospital chaplains served as subjects. During the time that the chaplains maintained contact with the patient they completed as much as possible of a data form and patient questionnaire. Ratings of emotional adjustment were used as the dependent variable; the subjects were divided into groups of high or low adjustment on the basis of the median score. Independent variables were ratings of discomfort, religious affiliation, religious beliefs, religious orientation, previous relationship with a dying person, financial security, perceived concern of others, age, sex, education, marital status, and type of disease. Multiple regression analysis indicated that the patient's physical condition, previous experience with dying persons, and interpersonal relationships were most predictive of emotional 
adjustment to a limited life expectancy. As in other investigations the data are not amenable to the recognition of trends or stages. However, the importance of the patient's interpersonal context is identified and parallels Kubler-Ross's emphasis.

\section{Studies of the Interaction of Psychological and Physiological Variables in the Terminally I11}

While all research with the terminally ill recognizes the presence of a physical illness, some investigators have focused attention on the interaction of changes in both physiological and psychological variables. Investigations such as Hinton's (1963) included both physical and psychological aspects of dying. One hundred and two patients whose illness was fatal within six months were compared with matched controls who were admitted to the hospital at about the same time, were approximately the same age, and had illnesses affecting the same organ system. Using data collected during weekly interviews, rating scales were used to measure physical discomfort, mental state, and personal history. The dying had a significantly higher occurrence of unrelieved physical distress and were significantly more depressed and more anxious. Both depression and anxiety showed a significant association with duration and discomfort of the illness. A graph of the last eight weeks of data revealed that there was a trend toward increasing depression and anxiety in the last two weeks of life, with anxiety being at a slightly lower level than depression. Discussing this increase in depression in the recent edition of his book, Dying (1972), Hinton suggests that depression may be related to persistant physical discomfort, loss of 
emotional support, or loss of roles. He cites Kubler-Ross in suggesting that the dying patient may grieve in preparation for his expected losses. Apparently Hinton did not find his data indicating increasing depression up to the time of death incompatible with Kubler-Ross's writing, although he found no evidence for the emotional void of a stage of acceptance.

Several types of comparisons were made in an investigation by Dudley, Verhey, Masuda, Maston and Holmes (1969) which followed 40 patients diagnosed with diffuse obstructive pulmonary syndrome (DOPS) over a period of four years. Physiological measures as well as an evaluation of total psychosocial assets by the Berle Index were recorded. In an auxiliary experiment 6 patients with DOPS were compared to 6 medical student controls on their response to noxious head stimulation. The DOPS patients showed mild hypoventilation with psychologic withdrawal while the controls differed significantly, showing hyperventilation with psychologic activation. The authors interpreted these results as an indication of successful denial and repression in the patients. An additional observational report was made that a range of defense mechanisms were employed by the patients with denial, repression, and isolation being the most common.

During the four years 29 subjects died. Based on the original data a comparison with surviving patients revealed that the probability of death was increased by low psychosocial and low physiologic assets in an additive relationship. Data were not presented in a form which could be examined for any stage variations. However, the authors noted that patients appeared to view death as comfortable and free of threat 
while staff and family with whom they interacted became emotionally upset by this attitude. This description resembles Kubler-Ross's description of the patient who has reached acceptance while others in his environment still need to maintain hope.

Physiological factors were found to be related to psychological. adjustment in an investigation of cancer patients by Davies, Quinlan, McKegney and Kimbal1 (1973). - Based on a semistructured interview with each of 46 patients, psychiatrists rated patients on a forty-six item checklist assessing mood, attitude, defense mechanisms, and degree of distress and adaptational capacities. These ratings were intercorrelated and factor analyzed, yielding four "psychiatric" factors labeled adaptive, apathetic-given up, dependent, and unaccepting of illness. Eight additional psychological tests were administered, and ratings of attitudes toward patients were obtained from nurses.

The authors noted that they were surprised to find that psychological variables yielded few significant findings in comparison with the physiological data. Significant findings did occur with impairment of brain functioning. Those with deficits in functioning survived longer, adapted more easily, slept better, and were less apathetic. It was suggested that these mildly impaired patients have lessened interests and concerns and an altered time sense which help to reduce anxiety and despair over future problems. High ratings on the apatheticgiven-up factor correlated with shorter survival time as well as a greater degree of illness, presence of hematological disorder rather than solid tumor, and reduced sleep. Thus the conclusion was made that 
both the psychological reaction and earlier death were related to the aspects of the disease.

Several possible interpretations of behavioral response in the terminally ill were discussed by the authors; behaviors could be viewed as expressions of motivational disturbances, as being associated with brain dysfunctioning, or as a combination of both. Davies et al. view Kubler-Ross's interpretation as a motivational perspective and comment. that their data provided no support for her view.

\section{Other Paradigms for Investigating the Terminally IIl}

In a slightly different approach to studying psychological changes prior to death, Lieberman (1965, 1966; Lieberman and Coplan, 1970) has reported investigations of aged populations. Lieberman has suggested that psychological changes accompanying the dying process can be conceptualized along a time line described as distance from death. In the initial study (1965) he used the Bender-Gestalt test, the Drawa-Person Test, a time reproduction task, and a projective test using line drawings to generate scores in the six areas of organizationdisorganization, ego energy, ego sufficiency-insufficiency, optimismpessimism, degree of affectivity, and intensity of activity. The test battery was administered to subjects every three to four weeks over a two and one-half year period. Comparisons were made between 8 subjects who lived less than a year, the Death Imminent (DI) group, and 17 subjects who survived at least a year, the Death Delayed (DD) group. The DI group showed significantly more decline in performance on the tasks measuring organization, ego energy, and ego sufficiency; the results 
indicated that the groups could be distinguished by changes in tasks reflecting adequacy of ego functioning, but were similar on measures of affect: Lieberman concluded that specific psychological changes could be identified which characterize the terminal phase of life.

Expanding the first study Lieberman (1966) obtained measures on 59 variables which he grouped into the areas of ego functions, body imagery, affect states, time perspective, self-image measures, personality traits, and measures of interpersonal area. Subjects were 22 elderly people who died one week to one year after completion of testing and a control group of 22 who were matched for living environment, age, sex, and country of origin. When the experimental group was compared with the control group no significant differences were found, but when the experimental group was divided into three groups according to the time interval before death, comparisons between experimental subgroups indicated that many measures yielded significant differences. Lieberman (1966) summarized:

In addition to the increased focus on body and the affective and personal-oriented dimensions. . ., modifications preceing death include lowered ego efficiency, less capacity for learning, and increased evidence of ego pathology. . . In the months preceding death, we see a less well-organized and seriously-conflicted individual, yet not a person who can reasonably be described as undergoing major personality modifications or strong regressive changes (p. 72).

Focusing on an attempt to clarify the emotional variables which differentiate people closer to death from those further away, Lieberman and Coplan (1970) investigated a third sample of the aged. Each subject was seen at least once a year for a twelve to fifteen hour testing and interview session over the three year investigation. Forty ambulatory 
aged persons who died within one year or less from the beginning of the study, the death-near (DN) group, were matched with 40 ambulatory aged persons who lived at least three years or more, the death-far (DF) group. Twenty-seven variables were grouped to measure cognitive functioning and the five affective realms of emotional states, orientation to emotional life, body imagery, self-concept, and time perception. Significant differences between groups were found in the areas of cognitive functioning, orientation to emotional life, and self image. Again, individuals could be differentiated according to their distance from death; Lieberman has suggested that there may be identifiable developmental changes which are part of the terminal phase of human life (1966). Lieberman's research and Kubler-Ross's observations are not directly comparable; whereas Kubler-Ross's patients were diagnosed as terminally ill and were seen in a hospital environment, Lieberman's subjects had no terminal medical diagnosis and did not live in an atmosphere of illness. In addition, Kubler-Ross's patients were probably significantly younger than Lieberman's aged population, although she provided no data on average age. In spite of these differences it is noteworthy that both authors perceived a process of change accompanying dying which both describe as natural and positive. While Lieberman identified both cognitive and affective changes in subjects approaching "natural" death, Kubler-Ross identified emotional response changes in patients facing the crisis of terminal illness.

A totally different methodology from those that have been cited. is represented by the psychological autopsy. As Kastenbaum and Weisman (1972) describe the technique, it involves an attempt ". . to 
reconstruct the pre-terminal and terminal phases of life for a patient who has recently died" (pp. 210-211). Staff of a geriatric hospital hold an interdisciplinary conference and use all available data to evaluate such variables as the patient's mental status prior to death, his social visibility and interpersonal relationships, and his attitudes, references, or premonitions of death. In an initial summary of 61 cases, Kastenbaum (1967) reported that there was not support for the assumption that most aged persons are in poor mental contact as they are dying. In addition, positive references to one's own death were more frequent than negative references, and those patients who were in the best mantal contact also tended to be most socially visible to personnel.

Their recent report (1972) from a sample of 80, focused on 35 cases whose orientation toward death was relatively clear from the data. Nineteen patients were categorized as accepting death; their preterminal behavior seemed to be influenced by their recognition of impending death and by an attitude of acceptance. Another group of 16 patients were categorized as interrupted by death. They appeared to have acknowledged the prospect of imminent death and to have chosen continued participation in daily life. Although not statistically significant, a trend was cited that some institutionalized geriatric patients proceed through a "microgenetic epicycle." In this epicycle the patient shows an acceptance of death as he first experiences the changes of hospital admission. However, he becomes involved in hospital activity and then displays the behaviors of those interrupted by death. Patients who survive into the ninth decade begin a quiet withdrawal which results in another period of acceptance. 
Kastenbaum and Weisman used the psychological autopsy only with geriatric patients; however, it is interesting that they perceived movement within the terminal phase of life which was related to both age and interpersonal context, one stage of which they labeled as acceptance.

No distinct pattern emerges from these quantitative investigations of the dying. Lieberman was the only investigator who made any hypothesis regarding aspects of ongoing change, and having designed a methodology capable of locating such data, he found evidence of developmental changes prior to death. However, the majority of the literature continues to be concerned with a static comparison between groups without any consideration of a time dimension.

Surveyors of this literature do not necessarily agree regarding their perceptions and interpretations of the results. Schulz and Aderman (1974) made a direct comparison between the stages described in On Death and Dying and the investigations cited above by Hinton, Achte and Vauhkonen, Lieberman (1965), and Kastenbaum and Weisman. The only strong similarity which Schulz and Aderman found was the frequently noted presence of depression in the dying. However, they failed to review Lieberman's later research, omitting the strongest statements of his developmental view. Although Schulz and Aderman appeared to have missed some of the commonality these studies have with Kubler-Ross's writing, they made some accurate observations. Kubler-Ross's stages are viewed as highly ambiguous, providing only subjective descriptions and specifying no assessment procedures for determing what stages a patient has passed through. Their final conclusion is that much more 
research is needed in order to have some clear understanding of the last period of life.

In summary, while empirical investigators may have deriwed a hypothesis from Kubler-Ross's writing or discussed their results in terms of her stages, there has been no attempt to specifically investigate the validity of her theory. In general, investigators have not designed studies which use paradigms which are able to perceive any developmental or phase-like aspects in the behavior of the terminally i11. Unfortunately, the longitudinal designs of those who have followed patients over a period of time require an investment of several years. The methodology used in the current study was designed as a compromise between the need for discriptions of patients at several points during their illness and the need to limit the investment of time in an exploratory study. 


\section{CHAPTER III}

\section{METHOD}

This chapter presents a detailed description of the experimental methodology, including information regarding the identification of subjects, the development of an appropriate Q-sort instrument, and the procedures relevant to the data collection and analyses.

\section{$\underline{\text { Subjects }}$}

A local physician who had worked with a university course on death and dying agreed to refer suitable patients to serve as sulpjects in this study. Patients were referred to the researcher after the doctor had confirmed that they were willing to discuss their illmess and participate in the investigation.

Subjects were two patient-spouse couples. In both couples the patient diagnosed with a potentially terminal disease was the wife. For clarity the term "subject" will be used to refer to both the husbands and wives involved in the study, while the term "patient" will be used to refer to the wife alone.

The couples were very similar on a variety of dimensions. Both women had been diagnosed as having breast cancer and had had a mastectomy. They both had also had professional training after high school, were residents of a rural farming community, and were living at home 
with their families and continuing their household routine. The husbands in each case had completed a college degree. The families appeared to fall in the middle class status, although Mr. and Mrs. B appeared to have slightly greater financial resources.

Mr. and Mrs. A are both forty-seven years old and have three teenaged children. Mrs. A is a registered nurse, although her illness has prevented her from being employed. Mr. A works in a helping profession which has given him extensive contact with terminally ill individuals. Mrs. A was diagnosed as having malignant cancer in 1968 and had a radical mastectomy. Since that time she has had several recurrences of cancer requiring radiation therapy and chemotherapy, as well as additional surgery. During the previous eighteen months she had been receiving chemotherapy for recurrent skin nodules, but approximately one month before the data collection, had asked that treatment be terminated due to side effects. Termination of the chemotherapy also involved a change of physician at her own request. She stated that, at the time she discontinued chemotherapy, she had no evidence of active cancer.

Mrs. B is a fifty-four year old housewife; her fifty-seven year old husband, Mr. B, owns a farm and is active in community and state affairs. They have five adult children with whom they maintain close contact. Mrs. B had a mastectomy for malignant cancer in January, 1973, followed by a series of cobalt treatments. Since that time she has had no further diagnosis of cancer. Mrs. B attended both business college and junior college, and her last full time employment was as a secretary. 


\section{Development of the Q-sort Instrument}

For the purpose of this study a thirty-six item Q-sort instrument was constructed according to Nunnally's (1967) criteria. Seventytwo first person statements designed to represent the Kubler-Ross stages, twelve statements per stage, were written to provide twice the number of items proposed for the final instrument. The item content was derived from interviews with terminally ill patients and the case descriptions included in On Death and Dying. The statements were randomized and given to nine judges to be categorized as representing denial, anger, depression, bargaining, acceptance, or hope. The judges were graduate students in clinical psychology and had attended a workshop directed by Dr. Kubler-Ross two weeks previous to the judging. In addition, the judges were provided with brief one paragraph descriptions of each stage, condensed from On Death and Dying. (Appendix A).

The seventy-two items written for the original item pool were each assigned to a Kubler-Ross category by the nine judges. The ratings were compiled, and the six items most frequently assigned to each stage were retained in the final thirty-six item Q-sort instrument; thus, items which were given the same stage label by all nine judges were selected in preference to those on which only eight judges agreed.

Table 1 presents the number of judges assigning each statement to a given category, the items selected for the Q-sort instrument, and the stage label given to each of these items. At least eight of the nine judges agreed on the category assignment of each of the items selected for five of the stages: hope, denial, anger, depression, and acceptance. However, in the category of bargaining since only four 
items received this level of judge agreement, two items were selected on the basis of agreement among six of the nine judges.

TABLE 1

JUDGE'S STAGE RATINGS OBTAINED

ON ORIGINAL ITEM POOL

\begin{tabular}{|c|c|c|c|c|c|c|c|}
\hline \multirow[b]{2}{*}{ Item $^{a}$} & \multirow[b]{2}{*}{ Hope } & \multicolumn{5}{|c|}{ Number of Judges Labeling Item As } & \multirow{2}{*}{$\begin{array}{l}\text { Category } \\
\text { Assigned } \\
\text { in } 36 \text { Item } \\
\text { Q-sort }^{\text {b }}\end{array}$} \\
\hline & & Denial & Anger & $\begin{array}{l}\text { Depres- } \\
\text { sion }\end{array}$ & $\begin{array}{l}\text { Bargain- } \\
\text { ing }\end{array}$ & $\begin{array}{l}\text { Accept- } \\
\text { ance }\end{array}$ & \\
\hline
\end{tabular}

Hope

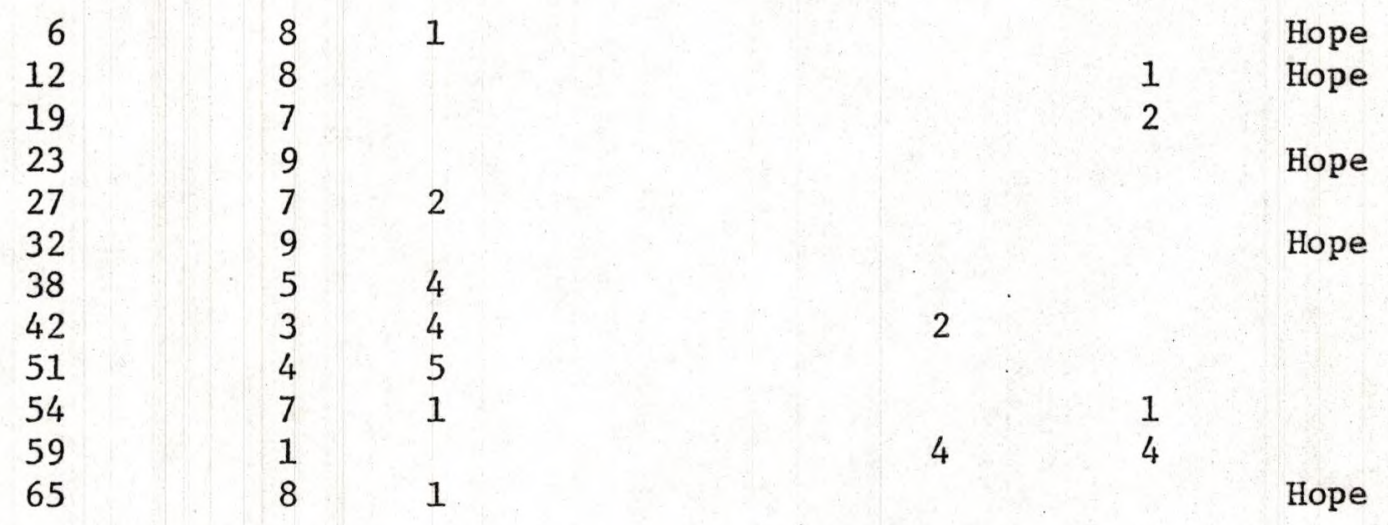

Denia1

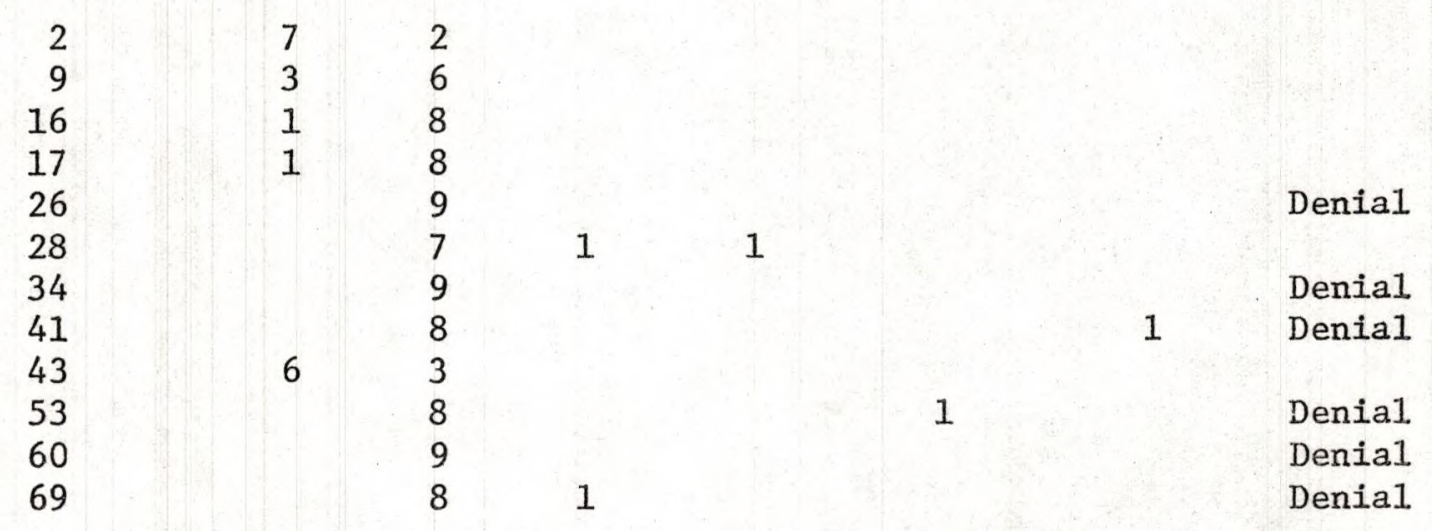


TABLE 1-- Continued

Number of Judges Labeling Item As

Category

Assigned

Depres- Bargain- Accept- in 36 Item

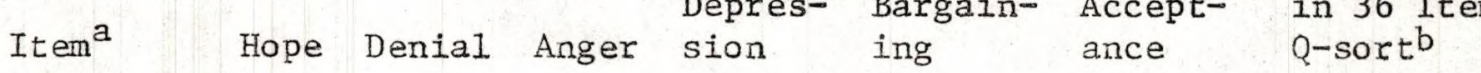

Anger

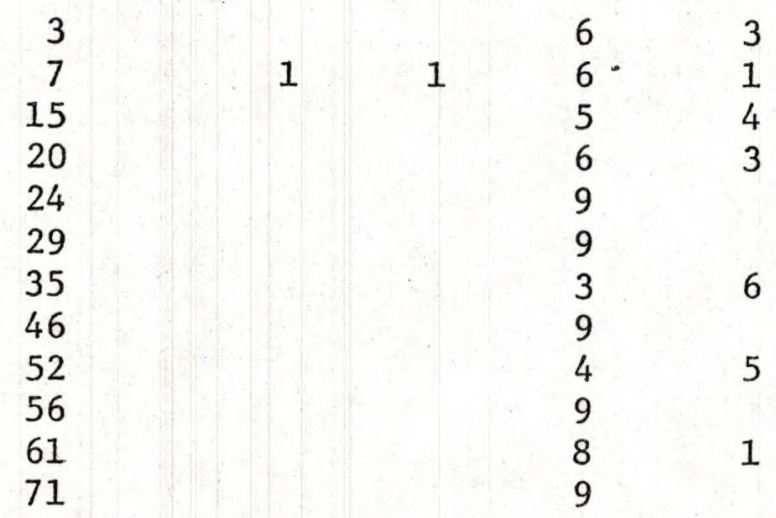

Anger

Anger

Anger

Anger

Anger

Anger

\section{Bargaining}

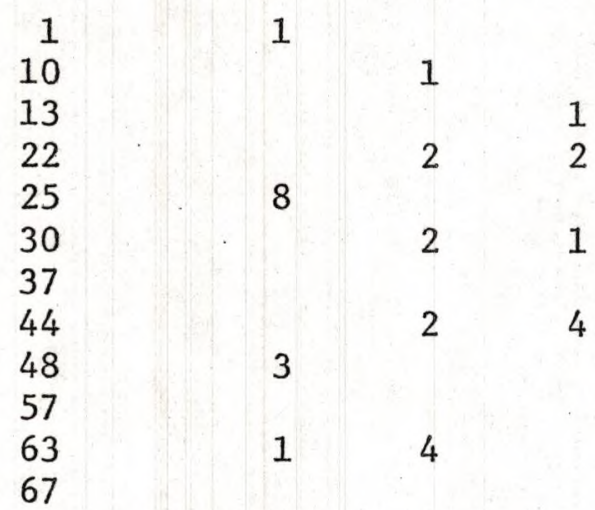

6

Bargaining Bargaining

4

Hope

Bargaining

1 Bargaining

Bargaining

3

Bargaining

\section{Acceptance}

5
11
18
31
39
47
50
55
58

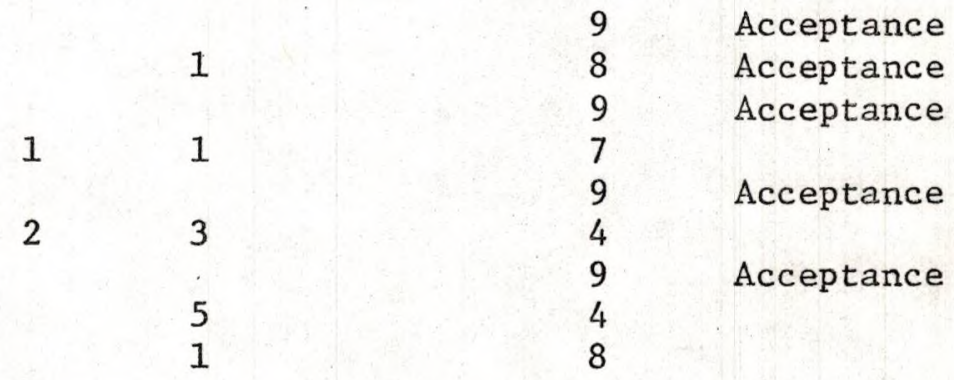


TABLE 1--Continued

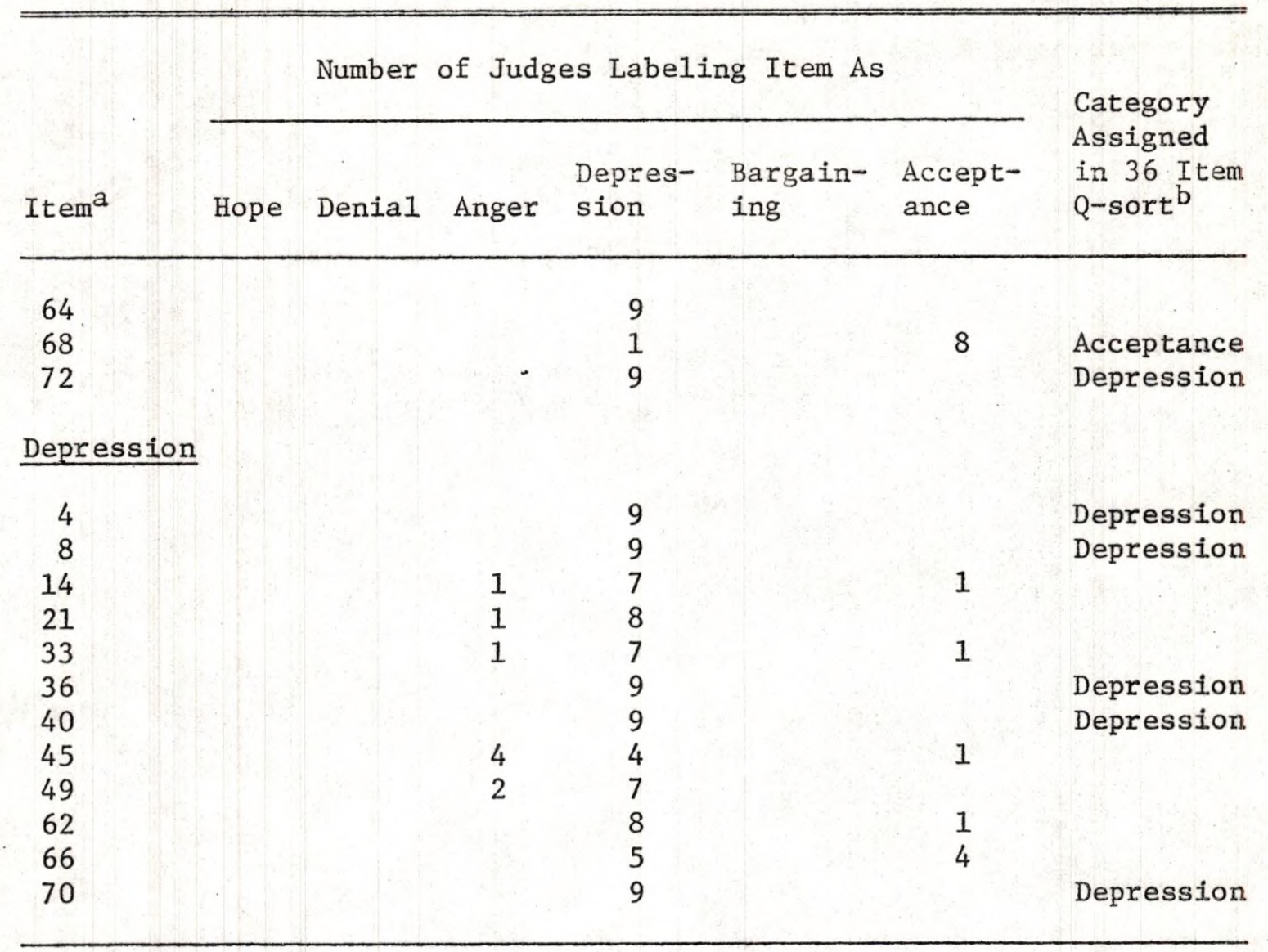

atems are grouped in the category they were written to represent.

$\mathrm{b}_{\mathrm{Bl}}$ anks indicate items not selected for the final Q-sort instrument.

It may be noted from Table 1 that judgements often included two main categories of labels within the items written to represent a particular stage; for example, on Item 38 judges appeared to have been able to eliminate all the labels other than hope and denial, but then had difficulty deciding between these two remaining categories. This type of split in rating may be an indication that a statement taken out of context may convey opposite emotional expressions. The narrowing of the 
field of choice is seen least within the items originally written to represent the stage of bargaining, and the items representing this category had the lowest judge agreement of those selected for the Q-sort. Interestingly, two items selected for the Q-sort were categorized with a stage label other than the one for which they were written. Item 25 was written to represent bargaining but was classified as expressing hope, while Item 72 was written to represent acceptance but was classified as representing depression.

The structured Q-sort items were then rewritten in the third person for use by the patient's spouse. Both forms were then restated in the past tense to provide clarification of meaning in describing past experiences. Four forms of the Q-sort were used: first person present: tense, first person past tense, third person present tense, and third person past tense (Appendix B).

The Q-sort items were each typed on a 3 in by 4 in card and assigned an identification number using a random number table. The same content was given the same number on each form of the Q-sort.

\section{Procedure of Data Collection}

The experimental procedure included three contacts with each couple. The first conversation provided an introduction to the research project. Then each subject was interviewed and asked to use the Q-sort to provide a description of the patient's current experience. The final session involved the use of the Q-sort instrument by each subject to provide additional descriptions of the patient. 
The patients were telephoned to confirm their willingness to participate in the study. At this time the wives were asked to obtain the consent of their husband to participate, and a brief description was provided of the number and type of experimental contacts that would be made.

An appointment was made at the couple's earliest convenience for the initial interviews, either at their home or at the university counseling center. Each subject was interviewed individually. The taped open-ended interview was designed to obtain the subject's description of the type of illness the patient had, what her reaction had been to the initial diagnosis, whether this response had changed over time, and what her daily life was like at the present time. The intent of the interview was to discover any subjective verbal report of changes which might be interpreted as paralleling those discussed by Kubler-Ross. The subject was then given the appropriate present tense Q-sort items and asked to use them to describe the patient during the past week (instructions are given in Appendix C).

At each administration the subject was instructed to rank order the items in terms of how accurately they described the patient during a specified period of time. Items were placed in six categories ranking from "1" (least like me/her) to "6" (most like me/her) and a normal distribution was approximated by requiring that $3,5,10,10,5$, and 3 items appear in categories 1 through 6 respectively.

Subjects were provided with labeled envelopes for each category and placed the ranked items in the appropriate envelope after completing the task. The researcher then recorded the item rank given to each item. 
While the first member of the couple worked on the Q-sort task, the second member was interviewed. Following the interview the second member also used the appropriate Q-sort items to describe the patient during the past week.

One to two weeks later the couple participated in their second experimental contact. Each subject worked in a separate room and proceeded at their own rate. They were first asked to again describe the patient during the past week, using the present tense Q-sort items. Then, using past tense items, the subjects were asked to describe the patient at four points in time since the diagnosis of cancer. These points were chosen subjectively on the basis of the taped interviews as those most likely to reflect any changing response to the illness. The patient was described by couple A:

1. After her mastectomy,

2. After a spot on her lung was discovered,

3. After her chest resection surgery,

4. Immediately before terminating chemotherapy.

Mr. and Mrs. B described the patient:

1. After her mastectomy,

2. After completing cobalt therapy,

3. During the middle of January, 1974,

4. Between medical checkups in the fall of 1974.

In summary, for both couples each member provided two descriptions of the present experience of the patient ("Describe yourself/her during the past week"). These two Q-sorts were designed as a check on the reliability of each individual's perception in considering a similar 
situation on two different occasions. In addition each individual also described their perception of the patient at four other times, yielding a total of twelve Q-sorts for each couple, six per person. To clarify further discussion Table 2 indicates abbreviated labels which will be used to identify each individual Q-sort.

TABLE 2

Q-SORT LABELS

Subject

Time Focus of Q-sort

Labe1.

\section{Case A}

Patient

Patient

Patient

Patient

Patient

Patient

Spouse

Spouse

Spouse

Spouse

Spouse

Spouse
First description of present

Second description of present

After mastectomy

After lung spot

After chest resection

During chemotherapy

First description of present

Second description of present

Af ter mastectomy

After lung spot

After chest resection

During chemotherapy
$\mathrm{AP}-1$

$\mathrm{AP}-2$

$\mathrm{AP}-3$

$\mathrm{AP}-4$

AP- 5

AP- 6

AS-1

AS-2

AS-3

AS- 4

AS-5

AS-6 
TABLE 2--Continued

Case B

\begin{tabular}{llr} 
Patient & First description of present & BP-1 \\
Patient & Second description of present & BP-2 \\
Patient & After mastectomy & BP-3 \\
Patient & After cobalt & BP-4 \\
Patient & During January, 1974 & BP-5 \\
Patient & Between medical checkups, fall 1974 & BP-6 \\
Spouse & First description of present & BS-1 \\
Spouse & Second description of present & BS-2 \\
Spouse & After mastectomy & BS-3 \\
Spouse & After cobalt & BS-4 \\
Spouse & During January, 1974 & BS-5 \\
Spouse & Between medical checkups, fall 1974 & BS-6 \\
\hline
\end{tabular}

\section{Procedure for Data Analysis}

The items of each Q-sort were assigned the rank or category in which they were placed as a score. Thus each Q-sort could be described by a set of thirty-six item scores. Product-moment correlations were. then computed among all the Q-sorts (represented by item scores) performed by a couple. These correlations were then submitted to a Qfactor analysis which will be described in detail in Chapter IV (Nunnally, 1967). 


\section{CHAPTER IV}

\section{RESULTS}

The Q-sorts performed by the subjects were examined from several perspectives. First an evaluation was made of both the consistency with which each individual could provide descriptions and the correspondence between each husband's and wife's descriptions. Then a Q-factor analysis was performed to delineate the relationship between each husband's and wife's Q-sorts, the changes that occurred in the Q-sorts across time probes, and the type of emotions the Q-sorts described. Finally, the usefulness of the structure built into the Q-sort instrument was evaluated.

\section{Evaluation of the Consistency of Q-sort Descriptions}

Each subject's two descriptions of the patient "during the past week" were used to determine intra-subject reliability. This was accomplished for Case A by correlating Q-sort AP-1 with AP-2 and AS-1 with AS-2. Likewise, for Case B, Q-sort BP-1 was correlated with BP-2 and BS-1 with BS-2. As indicated in Table 3, each individual subject maintained satisfactory reliability, or consistency, in his descriptions. That is, in describing the patient on two different occasions at least a week apart, the subjects made highly similar Q-sort rankings. 
TABLE 3

INTRA-SUBJECT AND INTER-SUBJECT CORRELATIONS CASES A AND B

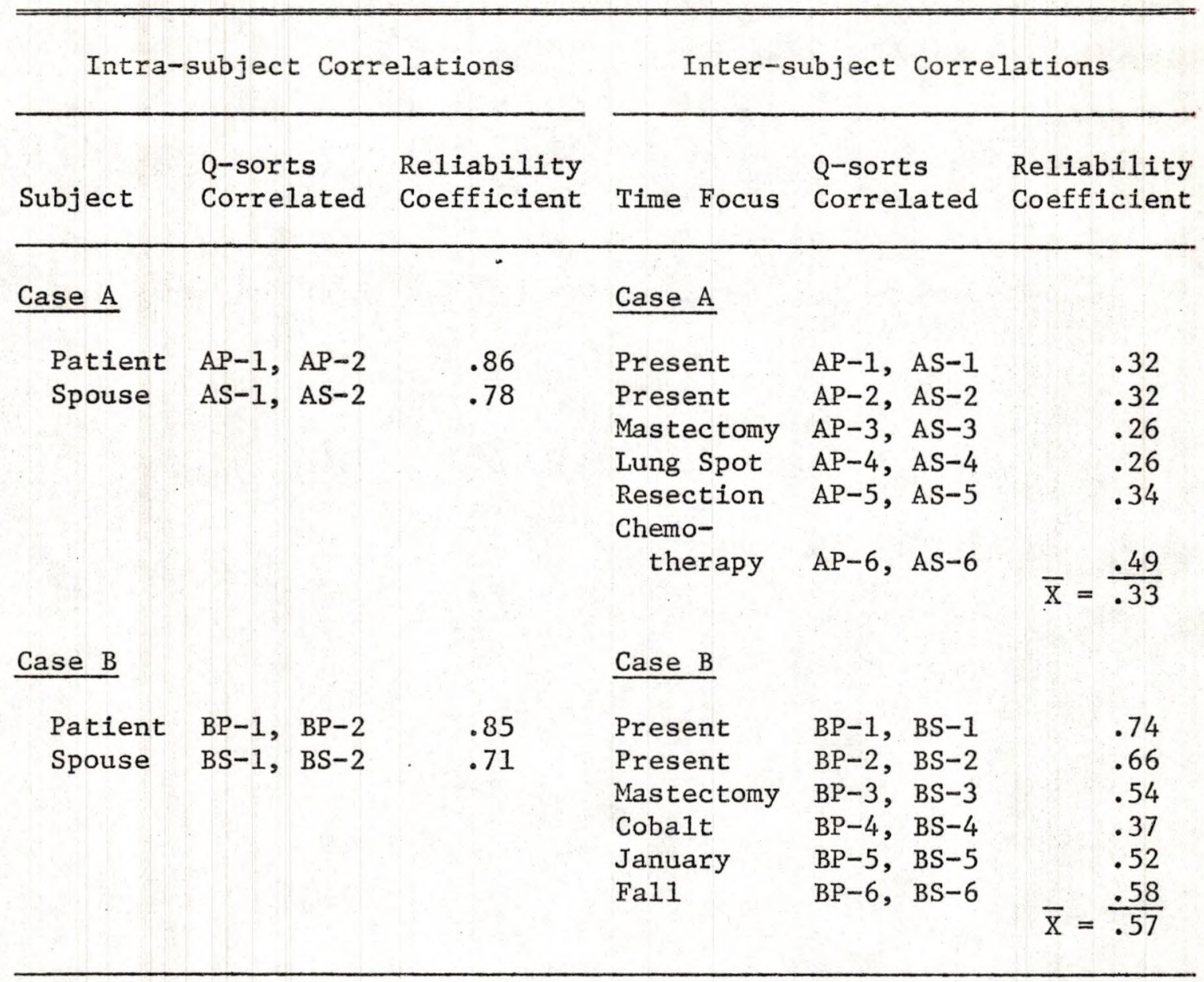

Table 3 also shows the intercorrelations of patient and spouse Q-sorts at parallel time probes. These inter-subject reliabilities indicate the degree of correspondence between the husband's and wife's descriptions of the same experience. For example, if the spouse was able to perceive the patient's experience in the same way she herself did, the correlation should be high. In general, the inter-subject reliabilities for each case were much lower than the intra-subject reliabilities, which would seem to indicate that the individuals in 
each couple did not share the same point of view, and ranked the Q-sort items in rather different ways. Thus, since each individual demonstrated their ability to provide consistent descriptions, the lower correlation between husband and wife must be assumed to be the result of different impressions of the patient's experience.

\section{Q-Factor Analytic Results}

For each case the ten Q-sorts performed at the second session $(\mathrm{AP}-2, \mathrm{AP}-3, \mathrm{AP}-4, \mathrm{AP}-5, \mathrm{AP}-6, \mathrm{AS}-2, \mathrm{AS}-3, \mathrm{AS}-4, \mathrm{AS}-5$, and $\mathrm{AS}-6$ for Case $\mathrm{A} ; \mathrm{BP}-2, \mathrm{BP}-3, \mathrm{BP}-4, \mathrm{BP}-5, \mathrm{BP}-6, \mathrm{BS}-2, \mathrm{BS}-3, \mathrm{BS}-4, \mathrm{BS}-5$, and $\mathrm{BS}-6$ for Case B) were intercorrelated and factor analyzed, using a principle components condensation procedure with unities in the diagonal of the correlation matrix (Nunnally, 1967). Factors were rotated to a varimax solution. The complete correlation matrix for each case and the unrotated factor loadings are presented in Appendices $\mathrm{E}$ and $\mathrm{F}$ respectively. It should be noted that the first descriptions of the patient's present experience (AP-1, $\mathrm{AS}-1, \mathrm{BP}-1, \mathrm{BS}-1$ ) were not included in the factor analysis since their high correlation with the other present description provided by the same subject indicated that they were redundant.

It is important to note that, in Q-methodology, factor analysis is based upon intercorrelations of people (in this case, perceptions of people or Q-sorts) rather than items (Stephenson, 1953). This leads to Q-sorts having factor loadings and items having factor scores, which is the reverse of the more common R-factor analysis. Factors obtained in the present study represent distinct, or orthogonal, points of view about the experience of terminal illness. Because unities were used as 
estimates of communality $\left(h^{2}\right)$ in the correlation matrix, a factor may be viewed as a real Q-sort, summarizing a group of similar descriptions of the patient's experience (Nunnally, 1967). The Q-sort defining each factor can then be obtained by ranking the normalized factor scores for the thirty-six items. The content of the Q-sort items ranking highest and lowest is used to label the particular perception of the patient. Tables 4 and 5 show the rotated factor loadings for Cases A and B, respectively. For Case A, four factors accounted for $87.8 \%$ of the total variation among the Q-sort descriptions. For Case B, three factors accounted for $80.1 \%$ of the common variance among the Q-sorts. The interpretation of factors was based upon significant Q-sort factor loadings exceeding .50 (Nunnally, 1967). These interpretations will be discussed separately for each case.

$\underline{\text { Case A }}$

In Case A, Factors I and III appeared to be patient factors. Factor I was defined by the patient's self-descriptions at all the time probes (AP-2, $\mathrm{AP}-3, \mathrm{AP}-4, \mathrm{AP}-5)$ except during her chemotherapy, while Factor III was defined by this remaining patient Q-sort (AP-6).

Factors II and IV, on the other hand, appeared to be spouse factors. Factor IV was defined primarily by the spouse's perception of the patient immediately after the mastectomy (AS-3), but also included significant loadings for the next two consecutive time probes (AS-4, AS-5). Factor II was also completely described by spouse Q-sorts and was defined by increasing factor loadings on the time probes from the discovery of the lung spot to the present (AS-4, AS-5, AS-6, AS-2). 
TABLE 4

ROTATED FACTOR LOADINGS: CASE A

Factors

\begin{tabular}{|c|c|c|c|c|c|c|}
\hline \multicolumn{2}{|c|}{ Q-sort } & I & II & III & IV & $h^{2}$ \\
\hline$A P-3$ & Mastectomy & $0.91^{a}$ & 0.02 & -0.18 & -0.02 & 0.87 \\
\hline $\mathrm{AP}-4$ & Lung Spot & $0.91^{\circ}$ & 0.18 & 0.15 & -0.05 & 0.89 \\
\hline $\mathrm{AP}-5$ & Resection & $\overline{0.85}$ & 0.07 & 0.35 & -0.23 & 0.89 \\
\hline$A P-6$ & Chemotherapy & 0.26 & 0.29 & 0.86 & 0.00 & 0.89 \\
\hline$A P-2$ & Present & 0.90 & 0.13 & 0.24 & -0.16 & 0.90 \\
\hline AS -3 & Mastectomy & 0.21 & 0.23 & -0.05 & -0.90 & 0.92 \\
\hline AS -4 & Lung Spot & 0.01 & 0.66 & 0.27 & -0.51 & 0.77 \\
\hline AS -5 & Resection & 0.16 & 0.78 & 0.10 & $-\overline{0.52}$ & 0.90 \\
\hline AS-6 & Chemotherapy & 0.00 & $\overline{0.86}$ & 0.33 & $-\overline{-0.03}$ & 0.86 \\
\hline $\mathrm{AS}-2$ & Present & 0.22 & $\overline{0.91}$ & -0.01 & -0.12 & 0.89 \\
\hline \multicolumn{2}{|c|}{ Percentage of } & 48.1 & 23.7 & 10.1 & 5.9 & \\
\hline
\end{tabular}

${ }^{a}$ Underlining indicates significant factor loadings used for interpretation of the factor.

The most important result of the configuration of the factors in Case $A$ is the fact that patient and spouse Q-sorts had high factor loadings on different factors. Thus, the patient and spouse appear to have had fundamentally different (orthogona1) perceptions of the patient's experience.

The factors obtained for Case A were labeled by examining the ideal Q-sorts compiled for each factor. In addition, the variance of all the factor scores for each item was calculated to identify the items which most differentiated the factors. Appendix $G$ lists the Q-sort defining each factor and indicates the factor score of each item. 
Items ranking high in the idealized Q-sort describing Factor I, the first patient factor, included "I pray to be we11," "I feel I have unfinished business," "I'm ready now for whatever happens," and "I'm busy planning for the future." This appeared to be a future oriented factor, perhaps reflecting hope. Statements characterizing the other patient factor, Factor III, include "I'm very resentful," "I feel the doctors are still searching for the right treatment for me," and "I'm so tired of being sick I could scream." These statements might be considered an expression of resentment or anger. Factor II, a spouse factor, was described by items such as "I'd give anything to be well," "I'm so tired of being sick I could scream," and "I have so little patience with people;" feelings of frustration seemed most prominent in these items. Factor IV, described by items such as "I'm just waiting," "I want my life to just quiet1y drift along," and "I feel nobody tells me what's going on," seemed to reflect a withdrawal from activity. Thus the patient's Q-sorts loaded on factors of hope and resentment or anger, while her spouse's Q-sorts loaded on factors of frustration and withdrawal.

It must be emphasized that these lables are based upon the combination of item contents and not upon the stage category to which the items were assigned in the structured Q-sort instrument. The context of the items was considered; so that while Item 3, "I feel I live under a shadow all the time," ranked high on both Factor I and Factor III, it was judged to have a much more negative connotation in the context of Factor III. 
An additional focus of the factor analytic results involved an examination of the factor loadings for any indication of systematic changes across the time line from the mastectomy to the present. If terminally ill patients not only experience different categories of emotional response but also change their response in systematic stages, it was expected that the categories would be reflected by the factor labels and the changing stage's by changes in factor loadings across Q-sorts. However, Factor II was the only factor which gave any indication of a systematic change in factor loadings. Since Factor II was a spouse factor, it appears that Mr. A perceived his wife as experiencing frustration from the time of her mastectomy to the present.

\section{TABLE 5}

ROTATED FACTOR LOADINGS: CASE B

\begin{tabular}{|c|c|c|c|c|c|}
\hline \multirow[b]{2}{*}{ Q-sort } & & \multicolumn{3}{|c|}{ Factors } & \multirow[b]{2}{*}{$h^{2}$} \\
\hline & & I & II & III & \\
\hline $\mathrm{BP}-3$ & Mastectomy & $0.90^{a}$ & -0.16 & 0.08 & 0.84 \\
\hline $\mathrm{BP}-4$ & Cobalt & 0.90 & -0.12 & 0.24 & 0.87 \\
\hline $\mathrm{BP}-5$ & January & 0.89 & -0.25 & 0.15 & 0.87 \\
\hline $\mathrm{BP}-6$ & Fal1 & -0.15 & 0.88 & -0.04 & 0.79 \\
\hline $\mathrm{BP}-2$ & Present & 0.78 & $-\overline{0.14}$ & 0.45 & 0.83 \\
\hline BS -3 & Mastectomy & 0.76 & 0.31 & 0.25 & 0.73 \\
\hline BS-4 & Cobalt & $\overline{0.12}$ & 0.17 & 0.88 & 0.81 \\
\hline BS-5 & January & 0.49 & -0.02 & 0.79 & 0.86 \\
\hline BS -6 & Fal1 & -0.08 & 0.87 & 0.12 & 0.77 \\
\hline $\mathrm{BS}-2$ & Present & $\underline{0.61}$ & $-\overline{0.17}$ & 0.48 & 0.63 \\
\hline \multicolumn{2}{|c|}{$\begin{array}{l}\text { Percentage of } \\
\text { total variance }\end{array}$} & 52.7 & 18.6 & 8.8 & \\
\hline
\end{tabular}

$\mathrm{a}_{\text {Underlining indicates significant factor loadings used for }}$ interpretation of the factor. 
Case B

In Case B, Factor II is the most clearly defined, describing both patient and spouse perceptions of the Fall of 1974 (BP-6, BS-6). Factor I is largely defined by the patient's self-perception at all the other time probes (BP-3, BP-4, BP-5, BP-2), although the spouse's perception of the time after the mastectomy (BS-3) and at the present (BS-2) both contribute to the factor. Factor III appears to be defined by the spouse's remaining Q-sorts which describe the patient's experience after cobalt (BS-4) and in January, 1974 (BS-5).

It is more difficult to summarize the factor analytic results for Case B. Patient and spouse have very congruent perceptions of the patient's experience during the Fall of 1974, as indicated by the Qsorts describing this period defining a single factor. Yet, the spouse's perception of two time probes is qualitatively different from any of the patient's descriptions, forming the third orthogonal factor. However, at three different time probes the patient's and spouse's parallel descriptions of the patient's experience do load on the same factors. The results of this factor analysis indicate much more congruence in the perception of $\mathrm{Mr}$. and Mrs. B than in the perception of Mr. and Mrs. A.

The labeling of factors for Case B followed the same procedure used in Case A. Appendix G lists the ideal Q-sort for each factor and the factor score of each item. The ideal Q-sort indicated that Factor I was described by items such as "I'm busy planning for the future," "I pray to be well," "I'm at peace with myself," and "I'II keep going as if nothing had happened." Factor I might be considered a quietly 
hopeful, forward looking orientation. "I feel nobody tells me what's going on," "Often I feel sad and depressed," "I'm very resentful," and "I pray to be well," all characterized Factor II. Feelings of both anger and depression seemed to be included. Factor III, defined by "I'm ready now for whatever happens," "I'm busy planning for the future," "I'm so lonely," "I feel there's so much I have to get done," and "I feel nobody tells me what's going on," was tentatively labeled as activity covering feelings of isolation. Since Q-sorts of both the patient and spouse loaded on Factors I and II, it appears that they both perceived periods of quiet hope, anger, and depression. However, only spouse Q-sorts loaded on the factor labeled as activity hiding isolation, indicating that the patient did not perceive this response.

The factor loadings for Case B were also examined for any evidence of trends. As in Case A, there was little evidence at all of any systematic change in factor loadings across the time line defined by the Q-sorts.

\section{Summary of Factor Analytic Results}

The patterns of factor loadings and factor labels described above suggest that, in both of the cases studied, the patients themselves described a predominant experience of hope (Case A--Factor I, Case B--Factor I). In Case A this experience extended across the entire time span except after chemotherapy (AP-6), and in Case B it extended across all the time probes except during the fall (BP-6). The spouse in Case B shared this perception of the patient's hope after the mastectomy (BS-3) and in the present (BS-2). 
Each patient also had an experience of anger (Case A--Factor III, Case B--Factor II); this appeared for patient A during her chemotherapy $(\mathrm{AP}-6)$ and for patient $\mathrm{B}$ during the fall $(\mathrm{BP}-6)$. Once again spouse B shared his wife's perception at this time probe (BS-6). The appearance of anger at these time probes is consistent with the subjective description of events which the couples provided during their interviews. Mrs. A experienced severe side effects from her chemotherapy and felt her doctor should have attempted other drug combinations and dosages. She eventually changed doctors and terminated all chemotherapy. Mrs. B also had described negative reactions to her doctor, these occurring in the fall of 1974. Because she was asked to return for another checkup sooner than it would normally occur, she became suspicious that a recurrence of the cancer was suspected and was angry that the doctor had not been honest with her. Apparently the problem actually involved scar tissue and the issue was resolved.

Both spouses described aspects of their wives' experience in terms of activity, providing descriptions labeled as withdrawal and activity to cover isolation. The spouse in Case A, rather than perceiving his wife's hope, had apparently perceived a great deal of activity in her, as indicated by his negative factor loadings on Factor IV. This perception was predominant for spouse A after the mastectomy (AS-3) and less clear after the lung spot was discovered and the chest resection performed (AS-4, AS-5). Spouse B, while having had congruent perceptions with his wife at three time probes, differed in perceiving her as coupling activity with feelings of isolation after her cobalt therapy (BS-4) and in January, 1974 (BS-6). While Spouse B shared his wife's 
perception of her period of anger, Spouse A perceived his wife's anger more in terms of frustration (Case A--Factor III), and he perceived this frustration as having continually increased over time since the discovery of the lung spot to the present (AS-4, AS-5, AS-6, AS-2).

Thus there appears to have been a remarkable similarity in the self-reports of two women living with potentially terminal illnesses. On the other hand, one husband shared his wife's perception of her illness in general, while the other's husband had essentially different perceptions of his wife's experience. It is also important to note that the wives' perceptions of their illness show some correspondence to the Kubler-Ross anger stage and identification of continuing hope. However, the experiences which only the husbands perceived were not labeled as corresponding to any components of the Kubler-Ross theory.

Although some of the factors obtained did receive Kubler-Ross labels, in neither case was there evidence of any trend which might represent a continuing shift in the emotional response of the patient.

\section{Adequacy of the Kubler-Ross Item Categories}

Nunna1ly (1967) suggests that after a structured Q-sort has been used, the functioning of the item categories may be checked by comparing the variance within each category to the total Q-sort variance on each Q-sort performed. If the structure of the items is being utilized, the variance within each category should always be smaller than the total variance, because items in the same category will be placed in the same area of the sort. Even if the items have been logically assigned to categories, the Q-sort design has done little to explain the ratings 
made by the subjects if the variance within categories is 1arger than the total variance.

The variance check was made on all the Q-sorts performed by both couples. Of the total twenty-four Q-sorts, a11 had at least one category in which the variance was as large or larger than the total variance. Table 6 presents the cell variances for each Q-sort. Due to the forced distribution, the total variance for all Q-sorts made with the same instrument will be equal, in this case 1.86 . The number of categories in a Q-sort with larger variances than the total ranged from one to three. It is apparent that the Q-sort rankings made by the subjects are not explained by the stage structure built into the Q-sort instrument. This conclusion was reflected in the fact that while several of the factors obtained were given labels paralleling Kubler-Ross stages (hope and anger), the items providing those labels often had not been assigned to the categories of hope or anger. Thus items categorized by judges as representing a particular Kubler-Ross stage were given a different connotation in their use by the subjects. In conclusion, it appears that the Kubler-Ross stage structure of the Q-sorts, as determined by the judges' ratings, was not useful in interpreting the perceptions of terminal illness provided by the patient and spouse of either couple. 
TABLE 6

CATEGORY VARIANCE FOR EACH Q-SORT

\section{Category}

Q-sort Hope Denial Anger Depression Bargaining Acceptance

Case A

$\begin{array}{lllllll}\mathrm{AP}-1 & 1.10 & 1.07 & 0.70 & 3.37 & 1.37 & 0.27 \\ \mathrm{AP}-2 & 0.67 & 1.87 & 0.67 & 3.20 & 1.20 & 1.20 \\ \mathrm{AP}-3 & 1.37 & 1.37 & 1.90 & 1.87 & 1.37 & 1.07 \\ \mathrm{AP}-4 & 1.37 & 2.97 & 1.47 & 2.70 & 0.97 & 1.07 \\ \mathrm{AP}-5 & 0.67 & 2.97 & 1.60 & 2.80 & 0.80 & 1.10 \\ \mathrm{AP}-6 & 1.77 & 0.57 & 2.56 & 2.30 & 0.57 & 0.70 \\ \mathrm{AS}-1 & 0.30 & 1.77 & 1.77 & 1.37 & 2.70 & 2.17 \\ \mathrm{AS}-2 & 0.97 & 1.90 & 1.77 & 1.10 & 1.37 & 1.37 \\ \mathrm{AS}-3 & 0.80 & 5.07 & 0.80 & 0.27 & 0.57 & 3.50 \\ \mathrm{AS}-4 & 0.67 & 4.67 & 2.67 & 1.37 & 0.30 & 0.80 \\ \mathrm{AS}-5 & 0.30 & 2.97 & 3.07 & 0.70 & 1.20 & 0.97 \\ \mathrm{AS}-6 & 0.16 & 1.37 & 3.47 & 0.40 & 1.90 & 0.57\end{array}$

Case B

\begin{tabular}{lllllll} 
BP-1 & 0.40 & 2.67 & 1.07 & 1.50 & 0.57 & 2.27 \\
BP-2 & 0.80 & 1.37 & 1.50 & 0.97 & 0.70 & 2.40 \\
BP-3 & 1.37 & 3.37 & 1.37 & 1.47 & 0.17 & 2.00 \\
BP-4 & 0.57 & 2.40 & 1.77 & 0.80 & 0.00 & 2.80 \\
BP-5 & 1.07 & 1.36 & 1.87 & 0.57 & 0.40 & 1.60 \\
BP-6 & 1.77 & 1.37 & 1.47 & 3.37 & 0.40 & 0.57 \\
BS-1 & 0.40 & 2.17 & 0.97 & 2.27 & 1.10 & 2.70 \\
BS-2 & 0.57 & 2.00 & 0.80 & 1.07 & 1.07 & 2.17 \\
BS-3 & 0.57 & 3.50 & 0.97 & 0.70 & 1.47 & 1.87 \\
BS-4 & 1.47 & 3.77 & 1.07 & 1.36 & 1.07 & 2.30 \\
BS-5 & 0.80 & 2.27 & 1.47 & 1.37 & 1.07 & 3.37 \\
BS-6 & 0.30 & 2.27 & 2.67 & 2.40 & 1.47 & 1.37 \\
\hline
\end{tabular}

Note: Total Q-sort variance is 1.86 for all Q-sorts. 


\section{CHAPTER V}

\section{DISCUSSION}

This investigation focused upon two major issues, the need for empirical validation of the Kubler-Ross stage theory and an evaluation of Q-methodology as an ethical and useful procedure for obtainimg data directly from those involved with the experience of terminal illness. While the results tend to support the use of Q-methodology, the implications regarding the Kubler-Ross theory are equivocal.

\section{Implications for the Kubler-Ross Stage Theory}

Although the factor analysis of Q-sorts did permit a deseription of individual perceptions of illness, these descriptions provided ambiguous evidence regarding the Kubler-Ross theory.

It appears that a close family member may be able to accurately perceive what a terminally ill patient will report as having been her own experience, but that this congruency of perceptions does not necessarily occur. In Case B, the husband's descriptions matched his wife's at three of the five time probes. In Case A, however, the husband's descriptions of his wife's experience during the illness were quite different from the descriptions she herself provided.

Differences in spouse and patient perceptions were also evident in the finding that patient factors were related to aspects of the 
Kubler-Ross theory whereas spouse factors were not. The factor analytic results indicated that both the patients described an experience of hope since the time of their diagnosis. The feeling of hope was broken by a period of anger mixed with resentment or depression, then feelings of hope were reinstated. These experiences described by both patients were labeled with terms used by Kubler-Ross, while experiences perceived by only the spouses were labeled as frustration, withdrawal, or isolation masked by activity. Thus, emotional responses described by Kubler-Ross occurred only in the descriptions obtained directly from the patients. This difference between first person and third person descriptions raises several questions. Perhaps the stages described by KublerRoss are present only in the perception of the illness which the patient himself experiences. Kubler-Ross based her conceptualization of a stage theory upon self-reports from the terminally ill, rather than upon third party descriptions. On the other hand, Kubler-Ross herself imposes some third party interpretation on the content of her interviews. Then are Kubler-Ross's perceptions more parallel to those of the patient or the spouse? It is interesting to note that the husband in Case $\mathrm{A}$ had been trained to work with the terminally ill and had even attended a workshop directed by Kubler-Ross, yet his descriptions revealed none of the Kubler-Ross stages. What then is the interaction between his training and his personal involvement in the illness? Perhaps spouse A was more aware of the actual experiences of the illness, while his wife defended herself with hope. On the other hand, his wife may not have openly shared her experiences with him. The interpretation of the congruence of descriptions in Case $B$ is also unclear. This matching may involve 
a well defended wife whose husband accepts her defenses at face value, or it may indicate an open communication of actual experience between wife and husband.

The differences between spouse and patient perceptions does support Kubler-Ross's emphasis upon the interpersonal context of the patient by indicating a possible source of difficulty for family members in their attempts to support a patient emotionally. It is difficult to be supportive if one does not understand what another person feels he is experiencing. Each spouse's need for his own defenses may also serve as a barrier to communication of feelings. In conclusion the difference between perceptions makes the use and interpretation of third party reports at least questionable in research regarding terminal illness. This study provides no evidence as to the accuracy of either patient or spouse descriptions in relation to actual experience, but it does indicate that perceptions of others cannot be equated with the perceptions of the patients.

A third source of ambiguity in the results is the failure of the factor analysis to indicate any stage-like trends across the time line of the Q-sorts. Although this failure might appear to be negative evidence regarding the theory, a possible explanation might be foumd in the fact that hope was the predominant experience described by the patients. Kubler-Ross describes the hope response as remaining essentiallఖ stable throughout the course of illness. The selection of the time probes may have influenced the descriptions of hope which were obtained. Time probes for several Q-sorts were focused after specific steps had been taken to treat a symptom (surgery, cobalt), when hope might be expected 
to be particularly prominent. In these two cases it may have been only the strong experience of anger that allowed another emotion to appear in the Q-sort descriptions. Since emotions recalled after a period of time tend to be only those which were most intense, smaller variations in feeling may have been overlooked by the subjects. It must also be noted that the subjects' recall of their experiences may be inaccurate. Rather than focusing on crisis situations, time probes might have been more effective if they had been spaced at some standard time interval. Thus, the results of this investigation do not provide any clear evidence for or against the hypothesis of stages within terminal illness. Any results of a small $\mathrm{n}$ study must also consider the limitations inherent in the selection of the subjects. It is difficult to argue in this case that the subjects were entirely representative of couples facing a terminal illness in one of the members. Although during their interviews both of the patients discussed having thought about dying, neither considered themselves to be facing an immiment death. As one woman stated, "You are more likely to die today, driving home in your car, than I am." Neither woman was bedridden or was currently limiting her daily routine. Mrs. A was in the process of painting several rooms of her home, while Mrs. B was starting her yearly greenhouse plants. Although this "non-dying" quality limits the ability to generalize, this same quality of health appeared to allow both women to talk quite frankly about their experiences when they were hospitalized and more acutely ill.

The remission aspects of the patients' illnesses may also have affected the type of stage changes which should have been anticipated. 
Hertzberg (1972) assumed that the Kubler-Ross theory was an accurate description of terminal illness. However, working on a hospital cancer unit led him to conclude that patients having a remission of symptoms did not seem to progress through stages in a linear fashion, but instead experienced a cyclic return to earlier stages. Hertzberg's observation suggests that by selecting time probes which focused on periods after treatment the patients were describing similar points on a cycle. Another unknown influence in the study involved the referral of these women to the investigator by the doctor, which occurred during the period of time they experienced anger directed toward him. The extent to which he perceived their anger, its effect upon his decision to refer them, and the effect of the patients' knowledge of the source of the referral are all possible sources of unknown bias upon the results. The generalization of the results is also limited by the extent to which the cases were similar. Two women under individual conditions described feelings which appear remarkably similar. They both, however, had had similar diagnoses and mastectomy surgery, lived in similar communities, and had families with similar educational and economic backgrounds.

\section{Implications for the Use of Q-methodology}

The second focus of the investigation involved an evaluation of the use of Q-methodology for investigations of terminal illness. In general, the use of Q-sorts for obtaining data directly from those involved in the experience of terminal illness was a satisfactory methodology. None of the subjects experienced any difficulty using the 
instrument, nor did item content appear to disturb them. These Q-sorts provided useful raw data from which the factor analyses were able to organize their perceptions of terminal illness.

While Q-methodology assisted in the organization of data, the structure of this particular Q-sort did not. It was evident that the structured basis of the Q-sort did not contribute to the interpretation of the results since the items within a category were not ranked together in the Q-sorts.

Despite the fact that the Q-sort structure was not used, further research with Q-methodology would seem to be indicated in an attempt to validate the Kubler-Ross theory. The present Q-sort instrument could be utilized with patients with a more acute terminal diagnosis and the results compared with those of the present study. Perhaps individuals experiencing a more imminent expectation of death would utilize the Q-sort differently. A longitudinal investigation using Q-sorts at regular intervals would allow subjects to continually provide descriptions of their present experiences, thus avoiding the inaccuracy of recall and the bias of only describing crises. Another Q-sort structured upon the Kubler-Ross theory might be organized using statements which more clearly reflect a definite emotional tone, rather than statements which ambiguously reflect multiple meanings. Perhaps simpler statements, short phrases, or adjectives could be used. In addition, untrained judges might provide a more appropriate structure for use by other untrained individuals. Perhaps individuals diagnosed as terminally ill themselves should serve as judges. 
Since Q-methodology permitted a statistical organization of the experiences of illness and yet required only a limited expense of time and emotion on the part of subjects, the investment required for longitudinal research appears justified. Further investigations might also consider psychological changes in long term acute illness, when a terminal diagnosis has not been made. Continuing research in the area of terminal illness requires that subjects be available for data collection over a period of time. Perhaps the most appropriate environment for longitudinal studies would be a teaching or research hospital. Specific recommendations for further research are that an attempt should be made to refine the Kubler-Ross structured Q-sort or provide another appropriate structure, and that longitudinal investigations of illness should be initiated utilizing Q-methodology.

\section{Summary}

A Q-methodological investigation of the experience of a potentially terminal illness indicated, at least for four individuals, that the following conclusions can be made:

1. Q-methodology is a statistically useful and ethical means of permitting the terminally ill and their family to provide descriptions of their perception of the patient's experience.

2. Patient and spouse perceptions of the patient's experience do not necessarily coincide, although they may do so.

3. Although factors describing the patients' own perception of their experience were labeled as hope and anger, terms used 
by Kubler-Ross, evidence regarding the potential validity of the Kubler-Ross stage theory was masked by the predominant feelings of hope. 
APPENDIX A

JUDGE'S RATING FORM FOR

ORIGINAL ITEM POOL 
Please classify the following 72 statements according to the KublerRoss stage which you feel they most represent. Brief descriptions of the stages are given below to guide your decisions. You may use any category any number of times.

Hope--This stage reflects the patient's feeling that his illness must have some meaning that will pay off eventually if he can only endure it a little longer. Hope may provide a rationalization for suffering or serve as a temporary form of denial. The patient holds the possibility open for some cure--the discovery of a new drug or the success of a research project.

Denia1--This stage reflects the patient's initial period of disbelief and may act as a buffer, allowing him to collect himself. Denial may also reflect periods when the patient can no longer consider the possibility of his own death and must put this consideration away in order to pursue life.

Anger--This stage reflects the patient's reaction to the interruption of his plans and activities and envy of those who can still enjoy 1ife. Anger may be directed randomly at anyone in his environment. Rage, envy, and resentment may all result from the loss of control over his own life.

Bargaining--This stage reflects an attempt to enter into some sort of agreement which may postpone the inevitable. The patient may ask to be rewarded for good behavior by an extension of life, lack of pain, or an opportunity to put his affairs in order.

Depression--This stage reflects the patient's sense of great loss. He may experience reactive depression to current physical losses and separation as well as preparatory depression to the impending loss.

Acceptance--This stage reflects an inner and outer peace without anger or depression. The patient is able to contemplate his coming end with a certain degree of quiet expectation. He is usually tired and quite weak. This stage is almost void of any feelings.

1. I'd give anything to be well.

2. My treatments have always worked.

3. I find it hard to get along with other people.

4. I feel totally dependent and helpless.

5. I'm at peace with myself.

6. Miracles do happen.

7. Sometimes I act as though my doctors don't know what they're doing. 
8. Giving up old relationships is so painful.

9. I'11 wake up and find it's all been a dream.

10. I have unfinished business.

11. I'm just waiting.

12. There is a purpose in my illness.

13. I just don't want any more pain.

14. I can't give to others as I did before.

15. I hate having to ask for things.

16. If it were serious I'd feel differently.

17. There's been a mistake.

18. I want my life to just quietly drift along.

19. Every event has a purpose in God's plan.

20. People don't care about me.

21. I feel as though I'm losing everything.

22. I still have places to go and things to do.

23. I expect they'11 soon discover new ways to treat my illness.

24. I have so little patience with people.

25. I pray to be well.

26. Not me, it can't be true.

27. I've always been lucky.

28. I'11 act as I would want to if I were ill.

29. I'm so tired of being sick I could scream.

30. There's so much I have to get done.

31. I really don't feel a need to form new friendships.

32. There are new scientific discoveries every day.

33. I worry about my family. 
34. I don't believe it.

35. It's awful when no one will talk to you.

36. I'm so 1onely.

37. Some things must be finished.

38. My illness can be controlled.

39. I'm content with what my life has been.

40. Often I feel sad and depressed.

41. I'11 keep going as if nothing had happened.

42. I've been feeling better lately.

43. Faith can heal all problems.

44. There are some things I refuse to give up.

45. I'm not able to do the things at home that I did before.

46. I'm very resentful.

47. I don't need other people as much as I used to.

48. I wouldn't care about anything else if my one wish could come true.

49. Sometimes I wonder who cares about me.

50. I'm ready now for whatever happens.

-51. There is a cure for my illness.

52. It's terrible to be dependent on other people.

53. I'm busy planning for the future.

54. Prayers are answered.

55. I'm not interested in new activities.

56. Why did God let this happen to me?

57. I would feel better if I thought my family could take care of themselves.

58. I have almost no feelings. 
59. I can help other people who have the same illness.

60. It isn't serious enough to tell other people about it.

61. People forget how sick I am.

62. I'm withdrawn from other people.

63. I'm making plans to meet any contingency.

64. My life is just an island.

65. The doctors are still searching for the right treatment for me.

66. I don't talk very much.

67. I'm trying to buy extra time.

68. Nothing bothers me any more.

69. People are overreacting to my illness.

70. I live under a shadow all the time.

71. Nobody tells me what's going on.

72. I've stopped doing anything. 
APPENDIX B

THIRTY-SIX ITEM Q-SORT STATEMENTS 


\section{FIRST PERSON PRESENT TENSE Q-SORT STATEMENTS}

1. I feel giving up old relationships is so painful.

2. I'm just waiting.

3. I feel I live under a shadow all the time.

4. I'm ready now for whatever happens.

5. Often I feel sad and depressed.

6. I feel some things must be finished.

7. I feel there's so much I have to get done.

8. I'm content with what my life has been.

9. I want my life to just quietly drift along.

10. I'm trying to buy extra time.

11. I feel there is a purpose in my illness.

12. I'm so lonely.

13. I feel I have unfinished business.

14. I feel totally dependent and helpless.

15. I wouldn't care about anything else if my one wish could come true.

16. I'd give anything to be well.

17. I feel miracles do happen.

18. I'11 keep going as if nothing had happened.

19. I'm so tired of being sick I could scream.

20. I think, not me, it can't be true.

21. Nothing bothers me anymore.

22. I feel the doctors are still searching for the right treatment for me.

23. I ask, Why did God let this happen to me?

24. I feel it isn't serious enough to tell other people about it.

25. I don't believe it.

26. I feel people are overreacting to my illness.

27. I'm at peace with myself.

28. I feel people forget how sick I am.

29. I pray to be well.

30. I have so little patience with people.

31. I feel there are new scientific discoveries every day.

32. I'm very resentful.

33. I've stopped doing anything.

34. I feel nobody tells me what's going on.

35. I expect they'll soon discover new ways to treat my illness.

36. I'm busy planning for the future.

\section{FIRST PERSON PAST TENSE Q-SORT STATEMENTS}

1. I felt giving up old relationships was so painful.

2. I was just waiting.

3. I felt I lived under a shadow all the time.

4. I was ready then for whatever happened.

5. Often I felt sad and depressed.

6. I felt some things must be finished.

7. I felt there was so much I had to get done.

8. I was content with what my life had been. 
9. I wanted my life to just quietly drift along.

10. I was trying to buy extra time.

11. I felt there was a purpose in my illness.

12. I was so lonely.

13. I. felt I had unfinished business.

14. I felt totally dependent and helpless.

15. I wouldn't have cared about anything else if my one wish could have come true.

16. I'd have given anything to be well.

17. I felt miracles do happen.

18. I kept going as if nothing had happened.

19. I was so tired of being sick I could have screamed.

20. I thought, not me, it can't be true.

21. Nothing bothered me anymore.

22. I felt the doctors were still searching for the right treatment for me.

23. I asked, Why did God let this happen to me?

24. I felt it wasn't serious enough to tell other people about it.

25. I didn't believe it.

26. I felt people were overreacting to my illness.

27. I was at peace with myself.

28. I felt people forgot how sick I was.

29. I prayed to be well.

30. I had so little patience with people.

31. I felt there were new scientific discoveries every day.

32. I was very resentful.

33. I had stopped doing anything.

34. I felt nobody told me what was going on.

35. I expected they would soon discover new ways to treat my illness.

36. I was busy planning for the future.

\section{THIRD PERSON PRESENT TENSE Q-SORT STATEMENTS}

1. She feels giving up old relationships is so painful.

2. She's just waiting.

3. She feels she lives under a shadow all the time.

4. She's ready now for whatever happens.

5. Often she feels sad and depressed.

6. She feels some things must be finished.

7. She feels there's so much she has to get done.

8. She's content with what her life has been.

9. She wants her life to just quietly drift along.

10. She's trying to buy extra time.

11. She feels there is a purpose in her illness.

12. She's so lonely.

13. She feels she has unfinished business.

14. She feels totally dependent and helpless.

15. She wouldn't care about anything else if her one wish could come true.

16. She'd give anything to be well. 
17. She feels miracles do happen.

18. She'll keep going as if nothing had happened.

19. She's so tired of being sick she could scream.

20. She thinks, not me, it can't be true.

21. Nothing bothers her anymore.

22. She feels the doctors are still searching for the right treatment for her.

23. She asks, Why did God let this happen to me?

24. She feels it isn't serious enough to tell other people about it.

25. She doesn't believe it.

26. She feels people are overreacting to her illness.

27. She's at peace with herself.

28. She feels people forget how sick she is.

29. She prays to be well.

30. She has so little patience with people.

31. She feels there are new scientific discoveries every day.

32. She's very resentful.

33. She's stopped doing anything.

34. She feels nobody tells her what's going on.

35. She expects they' 11 soon discover new ways to treat her illness.

36. She's busy planning for the future.

\section{THIRD PERSON PAST TENSE Q-SORT STATEMENTS}

1. She felt giving up old relationships was so painful.

2. She was just waiting.

3. She felt she lived under a shadow all the time.

4. She was ready then for whatever happened.

5. Of ten she felt sad and depressed.

6. She felt some things must be finished.

7. She felt there was so much she had to get done.

8. She was content with what her life had been.

9. She wanted her life to just quietly drift along.

10. She was trying to buy extra time.

11. She felt there was a purpose in her illness.

12. She was so lonely.

13. She felt she had unfinished business.

14. She felt totally dependent and helpless.

15. She wouldn't have cared about anything else if her one wish could have come true.

16. She would have given anything to be well.

17. She felt miracles do happen.

18. She kept going as if nothing had happened.

19. She was so tired of being sick she could have screamed.

20. She thought, not me, it can't be true.

21. Nothing bothered her anymore.

22. She felt the doctors were still searching for the right treatment for her.

23. She asked, Why did God let this happen to me?

24. She felt it wasn't serious enough to tell other people about it. 
25. She didn't believe it.

26. She felt people were overreacting to her illness.

27. She was at peace with herself.

28. She felt people forgot how sick she was.

29. She prayed to be well.

30. She had so little patience with people.

31. She felt there were new scientific discoveries every day.

32. She was very resentful.

33. She had stopped doing anything.

34. She felt nobody told her what was going on.

35. She expected they would soon discover new ways to treat her illness.

36. She was busy planning for the future. 
APPENDIX C

SUBJECT INSTRUCTIONS FOR PERFORMING Q-SORTS 


\section{WIFE'S INSTRUCTIONS}

These cards contain statements which reflect some of the experiences that seriously ill people sometimes have. Using the cards, please describe as accurately as possible how you have felt in general during the past week. Sort the statements into six piles or categories according to how well the statements represent your own experience.

On top of the deck are six category heading envelopes numbered "1" (least like me) through " $6 "$ (most like me). The headers also specify how many statements are to be placed in each category. Spread headers 1-6 left to right in a row in front of you. It will be easier if you first place the items in three categories: those clearly similar to you, those clearly dissimilar to you, and those not clearly classified. Then go through the statements again, trying to place each item in the category which best describes your judgement of its relative accuracy in describing you. Feel free to arrange and rearrange the cards so that, when you are finished, the three statements in category "6" represent you more than those in category "5" down to those least like you in category " 1 ".

Once again, please describe your experience during the past week to the best of your ability, realizing that some statements may describe you very we11, but others not at a11.

When you are satisfied with the final form, place the statements in the appropriate envelope. 


\section{HUSBAND'S INSTRUCTIONS}

These cards contain statements which reflect some of the experiences that seriously ill people sometimes have. Using the cards, please describe as accurately as possible how you think your wife has felt in general during the past week. Sort the statements into six piles or categories according, to how well the statements represent her own experience.

On top of the deck are six category heading envelopes numbered "1" (least like her) through "6" (most like her). The headers also specify how many statements are to be placed in each category. Spread headers 1-6 left to right in a row in front of you. It will be easier if you first place the items in three categories: those clearly similar to her, those clearly dissimilar to her, and those not clearly classified. Then go through the statements again, trying to place each item in the category which best describes your judgement of its relative accuracy in describing your wife. Feel free to arrange and rearrange the cards so that, when you are finished, the three statements in category "6" represent her more than those in category "5" down to those least like her in category " 1 ".

Once again, please describe her experience during the past week to the best of your ability, realizing that some statements may describe her very well, but others not at all.

When you are satisfied with the final form, place the statements in the appropriate envelope. 


\section{APPENDIX D}

Q-SORT RANKINGS 
TABLE ?

CASE A Q-SORTS

\begin{tabular}{|c|c|c|c|c|c|c|c|c|c|c|c|c|c|c|c|c|c|c|c|c|c|c|c|c|c|c|c|c|c|c|c|c|c|c|c|c|c|}
\hline \multirow{2}{*}{$\begin{array}{l}\text { Time } \\
\text { Focus }\end{array}$} & \multirow{2}{*}{$\begin{array}{l}\text { Q-Sort } \\
\text { Label }\end{array}$} & \multicolumn{36}{|c|}{ Q-sort Category Assigned to Item } \\
\hline & & 1 & 2 & 3 & 4 & 5 & 6 & 7 & 8 & 9 & 10 & 11 & 12 & 13 & 14 & 15 & 16 & 17 & 18 & 19 & 20 & 21 & 22 & 23 & 24 & 25 & 26 & 27 & 28 & 29 & 30 & 31 & 32 & 33 & 34 & 35 & 36 \\
\hline \multicolumn{38}{|l|}{ Patient } \\
\hline Present & AP-1 & 3 & 4 & 6 & 4 & 3 & 5 & 4 & 5 & 4 & 4 & 3 & 3 & 6 & 1 & 3 & 3 & 5 & 3 & 4 & 2 & 4 & 4 & 3 & 3 & 1 & 3 & 5 & 2 & 6 & 3 & 5 & 2 & 1 & 2 & 4 & 4 \\
\hline Present & AP-2 & 3 & 4 & 6 & 4 & 4 & 4 & 4 & 5 & 4 & 4 & 4 & 2 & 6 & 1 & 3 & 3 & 5 & 3 & 3 & 2 & 2 & 5 & 3 & 2 & 1 & 3 & 5 & 3 & 6 & 3 & 4 & 1 & 2 & 3 & 4 & 5 \\
\hline Mastectomy & $A P-3$ & 3 & 4 & 5 & 6 & 3 & 5 & 4 & 5 & 4 & 3 & 5 & 2 & 6 & 1 & 3 & 4 & 4 & 4 & 2 & 4 & 3 & 3 & 5 & 3 & 1 & 3 & 4 & 2 & 6 & 3 & 4 & 1 & 2 & 2 & 3 & 4 \\
\hline Lung Spot & $A P-4$ & 4 & 3 & 6 & 5 & 4 & 5 & 4 & 4 & 4 & 5 & 3 & 3 & 5 & 1 & 3 & 3 & 5 & 3 & 3 & 3 & 2 & 4 & 4 & 2 & 1 & 2 & 4 & 2 & 6 & 4 & 4 & 1 & 3 & 2 & 3 & 6 \\
\hline Resection & AP-5 & 3 & 3 & 6 & 4 & 3 & 5 & 4 & 4 & 3 & 5 & 4 & 2 & 4 & 1 & 3 & 3 & 5 & 3 & 4 & 2 & 2 & 5 & 4 & 2 & 1 & 3 & 5 & 2 & 6 & 3 & 4 & 1 & 3 & 4 & 4 & 6 \\
\hline Chemotherapy & AP-6 & 3 & 3 & 5 & 2 & 5 & 4 & 5 & 4 & 4 & 3 & 3 & 3 & 4 & 1 & 3 & 4 & 5 & 2 & 6 & 1 & 4 & 5 & 3 & 2 & 1 & 2 & 4 & 2 & 6 & 4 & 3 & 6 & 4 & 4 & 3 & 3 \\
\hline \multicolumn{38}{|l|}{ Spouse } \\
\hline Present & AS-1 & 4 & 2 & 3 & 5 & 4 & 5 & 6 & 4 & 3 & 2 & 3 & 3 & 5 & 2 & 3 & 6 & 4 & 3 & 6 & 2 & 1 & 3 & 2 & 3 & 1 & 5 & 4 & 5 & 4 & 4 & 3 & 4 & 1 & 4 & 4 & 3 \\
\hline Present & AS-2 & 4 & 2 & 3 & 4 & 5 & 5 & 5 & 3 & 3 & 3 & 2 & 4 & 6 & 3 & 4 & 6 & 4 & 4 & 6 & 1 & 1 & 2 & 3 & 3 & 1 & 2 & 4 & 5 & 4 & 5 & 3 & 3 & 2 & 3 & 4 & 4 \\
\hline Mastectomy & AS-3 & 2 & 1 & 3 & 5 & 3 & 5 & 5 & 4 & 2 & 3 & 3 & 3 & 4 & 3 & 4 & 4 & 4 & 6 & 4 & 1 & 3 & 5 & 2 & 4 & 1 & 6 & 6 & 3 & 3 & 4 & 5 & 3 & 2 & 2 & 4 & 4 \\
\hline Lung Spot & $A S-4$ & 4 & 2 & 5 & 3 & 5 & 5 & 4 & 4 & 2 & 4 & 1 & 4 & 4 & 3 & 5 & 5 & 3 & 3 & 6 & 2 & 3 & 3 & 1 & 2 & 1 & 6 & 4 & 4 & 3 & 4 & 3 & 4 & 2 & 3 & 3 & 6 \\
\hline Resection & AS-5 & 4 & 2 & 3 & 4 & 5 & 6 & 5 & 3 & 2 & 3 & 3 & 3 & 5 & 3 & 5 & 6 & 4 & 4 & 6 & 1 & 2 & 4 & 1 & 2 & 1 & 4 & 4 & 4 & 3 & 4 & 4 & 3 & 3 & 2 & 3 & 5 \\
\hline Chemotherapy & AS -6 & 4 & 2 & 5 & 4 & 4 & 4 & 5 & 3 & 3 & 2 & 3 & 4 & 5 & 4 & 5 & 6 & 3 & 2 & 6 & 1 & 2 & 3 & 1 & 2 & 1 & 3 & 3 & 4 & 4 & 5 & 3 & 4 & 3 & 6 & 3 & 4 \\
\hline
\end{tabular}


TABLE 8

CASE B Q-SORTS

Q-sort Category Assigned to Item

\begin{tabular}{|c|c|c|c|c|c|c|c|c|c|c|c|c|c|c|c|c|c|c|c|c|c|c|c|c|c|c|c|c|c|c|c|c|c|c|}
\hline \multirow{2}{*}{$\begin{array}{l}\text { Time } \\
\text { Focus }\end{array}$} & \multirow{2}{*}{$\begin{array}{l}\text { Q-Sort } \\
\text { Labe1 }\end{array}$} & \\
\hline & & 1 & 23 & 34 & 5 & 6 & 78 & 89 & 10 & 11 & 12 & 13 & 14 & 151 & 161 & $17 \quad 18$ & $18 \quad 19$ & 920 & $20 \quad 21$ & $21 \quad 22$ & 223 & 24 & 25 & 26 & 27 & 28 & 29 & 303 & 313 & 323 & 33 & 34 & 35 & 36 \\
\hline \multicolumn{35}{|l|}{ Patient } \\
\hline Present & BP-1 & 3 & 34 & 45 & 3 & 4 & 56 & 63 & 3 & 4 & 1 & 5 & 3 & 4 & 4 & 4 & 52 & 23 & 33 & 33 & 32 & 2 & 2 & 4 & 6 & 2 & 5 & 3 & 4 & 1 & 1 & 4 & 4 & 6 \\
\hline Present & BP-2 & 3 & 33 & 35 & 3 & 4 & 65 & 52 & 4 & 5 & 1 & 5 & 2 & 4 & 4 & 4 & 42 & 23 & 33 & 33 & 3 & 4 & 3 & 3 & 6 & 2 & 5 & 2 & 4 & 1 & 1 & 4 & 3 & 6 \\
\hline Mastectomy & $\mathrm{BP}-3$ & 3 & 33 & 35 & 2 & 4 & 44 & 42 & 3 & 5 & 1 & 4 & 1 & 4 & 4 & 45 & 53 & 33 & 34 & 4 & 35 & 1 & 3 & 5 & 6 & 2 & 6 & 2 & 4 & 2 & 4 & 3 & 3 & 6 \\
\hline Cobalt & BP-4 & 3 & 23 & 36 & 2 & 4 & 44 & 43 & 4 & 5 & 1 & 4 & 1 & 4 & 4 & 4 & 53 & 3 & 33 & 34 & 4 & 2 & 3 & 5 & 6 & 1 & 5 & 3 & 4 & 2 & 2 & 3 & 3 & 6 \\
\hline January & $B P-5$ & 3 & 31 & 15 & 2 & 4 & 44 & 43 & 3 & 5 & 1 & 5 & 2 & 4 & 4 & 4 & 5 & 34 & 43 & 3 & 3 & 3 & 3 & 4 & 6 & 2 & 6 & 3 & 4 & 1 & 2 & 2 & 4 & 6 \\
\hline Fall & $B P-6$ & 3 & 35 & 51 & 6 & 4 & 32 & 23 & 4 & 3 & 5 & 4 & 3 & 4 & 5 & 4 & 23 & 34 & 42 & 24 & 44 & 3 & 4 & 3 & 2 & 3 & 6 & 5 & 4 & 5 & 1 & 6 & 2 & 1 \\
\hline \multicolumn{35}{|l|}{ Spouse } \\
\hline Present & BS-1 & 4 & 24 & 45 & 2 & 3 & 56 & 63 & 4 & 5 & 2 & 3 & 1 & 2 & 4 & 45 & 5. 1 & 1. 3 & $3=$ & 54 & 4 & 2 & 3 & 4 & 6 & 3 & 4 & 3 & 4 & 3 & 1 & 4 & 3 & 6 \\
\hline Present & BS-2 & 3 & 24 & 45 & 3 & 4 & 63 & 34 & 4 & 4 & 3 & 4 & 2 & 3 & 5 & 34 & 4 & 23 & 3 & 53 & 3 & 2 & 4 & 5 & 6 & 3 & 5 & 2 & 4 & 1 & 1 & 3 & 4 & 6 \\
\hline Mastectomy & $B S-3$ & 3 & 13 & 33 & 3 & 4 & 64 & 44 & 3 & 4 & 3 & 6 & 1 & 4 & 5 & 43 & 32 & 26 & 63 & 34 & 44 & 2 & 1 & 4 & 5 & 2 & 5 & 3 & 5 & 2 & 2 & 4 & 3 & 5 \\
\hline Cobalt & $B S-4$ & 3 & 24 & 46 & 3 & 5 & 44 & 43 & 2 & 5 & 5 & 4 & 4 & 4 & $3=$ & 32 & 23 & 3 & 12 & 2 & 5 & 4 & 1 & 3 & 4 & 2 & 6 & 3 & 3 & 4 & 1 & 5 & 4 & 6 \\
\hline January & $8 s-5$ & 3 & 13 & 36 & 4 & 4 & 65 & 53 & 3 & 5 & 4 & 4 & 2 & 4 & 5 & 3 & 4 & 2 & 23 & 3 & 5 & 3 & 2 & 3 & 5 & 4 & 4 & 2 & 4 & 1 & 1 & 4 & 3 & 6 \\
\hline Pall & BS- 6 & 3 & 35 & 54 & 6 & 4 & 33 & 32 & 2 & 3 & 5 & 3 & 2 & 5 & 5 & 3 & 44 & 4 & 4 & 1 & 4 & 2 & 1 & 4 & 4 & 3 & 4 & 5 & 4 & 6 & 3 & 6 & 3 & 1 \\
\hline
\end{tabular}

pouse 
APPENDIX E

\section{Q-SORT CORRELATION MATRICES}


TABLE 9

Q-SORT CORRELATION MATRIX: CASE A

\begin{tabular}{|c|c|c|c|c|c|c|c|c|c|c|}
\hline \multirow[b]{2}{*}{ Q-sort } & \multicolumn{10}{|c|}{ Q-sort } \\
\hline & $\mathrm{AP}-2$ & $A P-3$ & $\mathrm{AP}-4$ & $\mathrm{AP}-5$ & $\mathrm{AP}-6$ & $\mathrm{AS}-2$ & $\mathrm{AS}-3$ & AS-4 & AS-5 & AS-6 \\
\hline $\mathrm{AP}-2$ & 1.00 & 0.75 & 0.85 & 0.88 & 0.45 & 0.32 & 0.34 & 0.25 & 0.34 & 0.22 \\
\hline $\mathrm{AP}-3$ & 0.75 & 1.00 & 0.75 & 0.65 & 0.15 & 0.20 & 0.26 & -0.03 & 0.15 & -0.02 \\
\hline $\mathrm{AP}-4$ & 0.85 & 0.75 & 1.00 & 0.76 & 0.38 & 0.35 & 0.23 & 0.26 & 0.34 & 0.17 \\
\hline $\mathrm{AP}-5$ & 0.88 & 0.65 & 0.86 & 1.00 & 0.46 & 0.26 & 0.35 & 0.28 & 0.34 & 0.22 \\
\hline $\mathrm{AP}-6$ & 0.45 & 0.15 & 0.38 & 0.46 & 1.00 & 0.37 & 0.14 & 0.34 & 0.37 & 0.49 \\
\hline AS -2 & 0.32 & 0.20 & 0.35 & 0.26 & 0.37 & 1.00 & 0.42 & 0.58 & 0.78 & 0.71 \\
\hline AS-3 & 0.34 & 0.26 & 0.23 & 0.35 & 0.14 & 0.42 & 1.00 & 0.49 & 0.65 & 0.25 \\
\hline AS -4 & 0.25 & -0.03 & 0.26 & 0.28 & 0.34 & 0.54 & 0.49 & 1.00 & 0.77 & 0.54 \\
\hline AS- 5 & 0.34 & 0.15 & 0.34 & 0.34 & 0.37 & 0.78 & 0.65 & 0.77 & 1.00 & 0.68 \\
\hline AS -6 & 0.22 & -0.02 & 0.17 & 0.22 & 0.49 & 0.71 & 0.25 & 0.65 & 0.68 & 1.00 \\
\hline
\end{tabular}


TABLE 10

Q-SORT CORRELATION MATRIX: CASE B

\begin{tabular}{|c|c|c|c|c|c|c|c|c|c|c|}
\hline \multirow[b]{2}{*}{ Q-sort } & \multicolumn{10}{|c|}{ Q-sort } \\
\hline & $\mathrm{AP}-2$ & $\mathrm{AP}-3$ & $\mathrm{AP}-4$ & $\mathrm{AP}-5$ & $\mathrm{AP}-6$ & AS-2 & AS-3 & $\mathrm{AS}-4$ & AS-5 & AS-6 \\
\hline $\mathrm{BP}-2$ & 1.00 & 0.71 & 0.78 & 0.80 & -0.18 & 0.66 & 0.63 & 0.43 & 0.74 & -0.18 \\
\hline $\mathrm{BP}-3$ & 0.71 & 1.00 & 0.89 & 0.83 & -0.32 & 0.57 & 0.54 & 0.23 & 0.48 & -0.12 \\
\hline BP-4 & 0.78 & 0.89 & 1.00 & 0.86 & -0.26 & 0.61 & 0.60 & 0.37 & 0.60 & -0.09 \\
\hline $\mathrm{BP}-5$ & 0.80 & 0.83 & 0.86 & 1.00 & -0.34 & 0.55 & 0.60 & 0.28 & 0.52 & -0.28 \\
\hline BP-6 & -0.18 & -0.32 & -0.26 & -0.34 & 1.00 & -0.20 & 0.12 & 0.09 & -0.14 & 0.58 \\
\hline$B S-2$ & 0.66 & 0.57 & 0.62 & 0.55 & -0.20 & 1.00 & 0.55 & 0.31 & 0.69 & -0.15 \\
\hline$B S-3$ & 0.63 & 0.54 & 0.60 & 0.60 & 0.12 & 0.55 & 1.00 & 0.31 & 0.60 & 0.14 \\
\hline$B S-4$ & 0.43 & 0.23 & 0.37 & 0.28 & 0.09 & 0.31 & 0.31 & 1.00 & 0.62 & 0.23 \\
\hline BS-5 & 0.74 & 0.48 & 0.60 & 0.52 & -0.14 & 0.59 & 0.60 & 0.62 & 1.00 & 0.05 \\
\hline BS-6 & -0.18 & -0.12 & -0.09 & -0.28 & 0.58 & -0.15 & 0.14 & 0.23 & 0.05 & 1.00 \\
\hline
\end{tabular}


APPENDIX F

UNROTATED FACTOR LOADINGS 
TABLE 11

UNROTATED FACTOR LOADINGS: CASE A

\begin{tabular}{|c|c|c|c|c|c|}
\hline \multirow[b]{2}{*}{ Q-sort } & \multicolumn{4}{|c|}{ Factor } & \multirow[b]{2}{*}{$h^{2}$} \\
\hline & I & II & III & IV & \\
\hline$A P-3$ & 0.57 & -0.66 & -0.19 & 0.27 & 0.87 \\
\hline$A P-4$ & 0.77 & -0.53 & 0.05 & 0.11 & 0.89 \\
\hline$A P-5$ & 0.78 & -0.50 & 0.06 & -0.18 & 0.89 \\
\hline$A P-6$ & 0.59 & 0.06 & 0.63 & -0.37 & 0.89 \\
\hline $\mathrm{AP}-2$ & 0.79 & -0.52 & 0.04 & -0.03 & 0.90 \\
\hline AS -3 & 0.59 & 0.20 & -0.64 & -0.34 & 0.92 \\
\hline AS -4 & 0.66 & 0.55 & -0.08 & -0.15 & 0.77 \\
\hline$A S-5$ & 0.78 & 0.50 & -0.20 & 0.04 & 0.90 \\
\hline AS- 6 & 0.62 & 0.58 & 0.32 & 0.19 & 0.86 \\
\hline AS-2 & 0.72 & 0.44 & 0.00 & 0.41 & 0.89 \\
\hline
\end{tabular}

TABLE 12

UNROTATED FACTOR LOADINGS: CASE B

\begin{tabular}{lrrrr}
\hline & & Factor & \\
& & & \\
& & & \\
& & & \\
& & & \\
& & & \\
& & & & \\
& & & & \\
BP-sort & & & & \\
BP-4 & 0.85 & -0.16 & -0.31 & 0.84 \\
BP-5 & 0.91 & -0.06 & -0.20 & 0.87 \\
BP-6 & 0.88 & -0.21 & -0.21 & 0.87 \\
BP-2 & -0.28 & 0.79 & -0.30 & 0.79 \\
BS-3 & 0.91 & 0.01 & 0.03 & 0.83 \\
BS-4 & 0.73 & 0.34 & -0.29 & 0.73 \\
BS-5 & 0.48 & 0.50 & 0.57 & 0.81 \\
BS-6 & 0.80 & 0.27 & 0.39 & 0.86 \\
BS-2 & -0.15 & 0.84 & -0.20 & 0.63 \\
& 0.78 & 0.01 & 0.14 & \\
\hline
\end{tabular}


APPENDIX G

NORMALIZED FACTOR SCORES

AND Q-SORT ARRAYS 


\section{CASE A: FACTOR I}

Normalized

Factor

Score:

2.06

1.56

1.54

1.26

1.13

0.98

0.93

0.87

0.80

0.68

0.64

0.57

0.45

0.42

0.32

0.30

0.24

0.04

$-0.04$

$-0.13$

$-0.16$

$-0.16$

$-0.27$

$-0.33$

$-0.61$

$-0.74$

$-0.78$

$-0.79$

$-0.92$

$-0.96$

$-0.96$

$-1.01$

$-1.02$

$-1.66$

$-1.95$

$-2.31$
Item

29. I pray to be well.

3. I feel I live under a shadow all the time.

13. I feel I have unfinished business.

4. I'm ready now for whatever happens.

36. I'm busy planning for the future.

17. I feel miracles do happen.

23. I ask, Why did God let this happen to me?

6. I feel some things must be finished.

8. I'm content with what my life has been.

11. I feel there is a purpose in my illness.

27. I'm at peace with myself.

10. I'm trying to buy extra time.

9. I want my life to just quietly drift along.

31. I feel there are new scientific discoveries every day.

22. I feel the doctors are still searching for the right treatment for me.

2. I'm just waiting.

7. I feel there's so much I have to get done.

35. I expect they'11 soon discover new ways to treat my illness.

18. I'11 keep going as if nothing had happened.

20. I think, not me, it can't be true.

1. I feel giving up old relationships is so painful.

5. Often I feel sad and depressed.

30. I have so little patience with people.

16. I'd give anything to be well.

15. I wouldn't care about anything else if my one wish could come true.

24. I feel it isn't serious enough to tell other people about it.

33. I've stopped doing anything.

34. I feel nobody tells me what's going on.

19. I'm so tired of being sick I could scream.

26. I feel people are overreacting to my illness.

28. I feel people forget how sick I am.

21. Nothing bothers me anymore.

12. I'm so lonely.

25. I don't believe it.

14. I feel totally dependent and helpless.

32. I'm very resentfu1. 
CASE A: FACTOR II

Normalized

Factor

Score:

2.30

1.93

1.67

1.18

1.14

1.10

1.04

0.94

0.94

0.86

0.59

0.50

0.42

0.34

$-0.02$

$-0.07$

$-0.11$

$-0.26$

$-0.30$

$-0.31$

$-0.40$

$-0.44$

$-0.52$

$-0.55$

$-0.56$

$-0.73$

$-0.77$

$-0.78$

$-0.81$

$-0.91$

$-0.92$

$-1.23$

$-1.38$

$-1.40$

$-1.56$

$-1.56$
Item

16. I'd give anything to be well.

19. I'm so tired of being sick I could scream.

13. I feel I have unfinished business.

28. I feel people forget how sick I am.

30. I have so little patience with people.

5. Often I feel sad and depressed.

15. I wouldn't care about anything else if my one wish could come true.

6. I feel some things must be finished.

7. I feel there's so much I have to get done.

1. I feel giving up old relationships is so painful.

12. I'm so lonely.

36. I'm busy planning for the future.

4. I'm ready now for whatever happens.

14. I feel totally dependent and helpless.

3. I feel I live under a shadow all the time.

32. I'm very resentful.

29. I pray to be well.

35. I expect they'11 soon discover new ways to treat my illness.

34. I feel nobody tells me what's going on.

17. I feel miracles do happen.

18. I'11 keep going as if nothing had happened.

9. I want my life to just quietly drift along.

27. I'm at peace with myself.

31. I feel there are new scientific discoveries every day.

8. I'm content with what my life has been.

33. I've stopped doing anything.

26. I feel people are overreacting to my illness.

10. I'm trying to buy extra time.

24. I feel it isn't serious enough to tell other people about it.

11. I feel there is a purpose in my illness.

2. I'm just waiting.

23. I ask, Why did God let this happen to me?

22. I feel the doctors are still searching for the right treatment for me.

20. I think, not me, it can't be true.

25. I don't believe it.

21. Nothing bothers me anymore. 
CASE A: FACTOR III

Normalized

Factor

Score:

2.12

1.75

1.68

1.55

1.32

1.31

0.90

0.87

0.84

0.71

0.49

0.32

0.26

0.25

0.20

0.06

$-0.01$

$-0.15$

$-0.23$

$-0.24$

$-0.30$

$-0.32$

$-0.34$

$-0.38$

$-0.41$

$-0.48$

$-0.54$

$-0.79$

$-0.89$

$-0.92$

$-1.15$

$-1.18$

$-1.26$

$-1.49$

$-1.65$

$-1.92$

\section{Item}

32. I'm very resentful.

22. I feel the doctors are still searching for the right treatment for me.

19. I'm so tired of being sick I could scream.

3. I feel I live under a shadow all the time.

29. I pray to be well.

34. I feel nobody tells me what's going on.

33. I've stopped doing anything.

17. I feel miracles do happen.

21. Nothing bothers me anymore.

5. Often I feel sad and depressed.

7. I feel there's so much I have to get done.

27. I'm at peace with myself.

10. I'm trying to buy extra time.

8. I'm content with what my life has been.

9. I want my life to just quietly drift along.

36. I'm busy planning for the future.

30. I have so little patience with people.

2. I'm just waiting.

35. I expect they'll soon discover new ways to treat my illness.

12. I'm so lonely.

15. I wouldn't care about anything else if my one wish could come true.

26. I feel people are overreacting to my illness.

6. I feel some things must be finished.

1. I feel giving up old relationships is so painful.

31. I feel there are new scientific discoveries every day.

11. I feel there is a purpose in my illness.

16. I'd give anything to be well.

23. I ask, Why did God let this happen to me?

25. I don't believe it.

13. I feel I have unfinished business.

28. I feel people forget how sick I am.

24. I feel it isn't serious enough to tell other people about it.

14. I feel totally dependent and helpless.

20. I think, not me, it can't be true.

18. I'11 keep going as if nothing had happened.

4. I'm ready now for whatever happens. 


\section{CASE A: FACTOR IV}

Normalized

Factor

Score:

1.51

1.45

1.38

1.37

1.29

1.08

1.05

1.02

0.76

0.56

0.51

0.46

0.44

0.37

0.27

0.23

0.19

0.16

0.08

$-0.20$

$-0.25$

$-0.27$

$-0.27$

$-0.30$

$-0.33$

$-0.36$

$-0.41$

$-0.50$

$-0.53$

$-0.86$

$-1.04$

$-1.09$

$-1.50$

$-1.73$

$-1.81$

$-2.85$

\section{Item}

2. I'm just waiting.

9. I want my life to just quietly drift along.

23. I ask, Why did God let this happen to me?

34. I feel nobody tells me what's going on.

20. I think, not me, it can't be true.

25. I don't believe it.

29. I pray to be well.

1. I feel giving up old relationships is so painful.

33. I've stopped doing anything.

11. I feel there is a purpose in my illness.

13. I feel I have unfinished business.

3. I feel I live under a shadow all the time.

12. I'm so lonely.

28. I feel people forget how sick I am.

5. Often I feel sad and depressed.

30. I have so little patience with people.

14. I feel totally dependent and helpless.

16. I'd give anything to be well.

32. I'm very resentful.

17. I feel miracles do happen.

10. I'm trying to buy extra time.

24. I feel it isn't serious enough to tell other people about it.

21. Nothing bothers me anymore.

35. I expect they'11 soon discover new ways to treat my illness.

4. I'm ready now for whatever happens.

19. I'm so tired of being sick I could scream.

8. I'm content with what my life has been.

15. I wouldn't care about anything else if my one wish could come true.

7. I feel there's so much I have to get done.

36. I'm busy planning for the future.

6. I feel some things must be finished.

31. I feel there are new scientific discoveries every day.

22. I feel the doctors are still searching for the right treatment for me.

18. I'1l keep going as if nothing had happened.

27. I'm at peace with myself.

26. I feel people are overreacting to my illness. 


\section{CASE B: FACTOR I}

Normalized

Factor

Score:

1.94

1.60

1.31

1.09

1.07

1.07

0.96

0.93

0.88

0.84

0.80

0.78

0.58

0.47

0.42

0.23

0.23

0.12

$-0.08$

$-0.37$

$-0.41$

$-0.41$

$-0.41$

$-0.43$

$-0.49$

$-0.56$

$-0.64$

$-0.69$

$-0.73$

$-0.73$

$-0.77$

$-1.42$

$-1.44$

$-1.49$

$-2.07$

$-2.16$

\section{Item}

27. I'm at peace with myself.

29. I pray to be well.

36. I'm busy planning for the future.

23. I ask, Why did God let this happen to me?

18. I'll keep going as if nothing had happened.

13. I feel I have unfinished business.

26. I feel people are overreacting to my illness.

20. I think, not me, it can't be true.

16. I'd give anything to be well.

7. I feel there's so much I have to get done.

31. I feel there are new scientific discoveries every day.

11. I feel there is a purpose in my illness.

17. I feel miracles do happen.

4. I'm ready now for whatever happens.

15. I wouldn't care about anything else if my one wish could come true.

6. I feel some things must be finished.

8. I'm content with what my life has been.

10. I'm trying to buy extra time.

21. Nothing bothers me anymore.

25. I don't believe it.

22. I feel the doctors are still searching for the right treatment for me.

34. I feel nobody tells me what's going on.

1. I feel giving up old relationships is so painful.

35. I expect they' 11 soon discover new ways to treat my illness.

30. I have so little patience with people.

9. I want my life to just quietly drift along.

19. I'm so tired of being sick I could scream.

33. I've stopped doing anything.

2. I'm just waiting.

3. I feel I live under a shadow a11 the time.

5. Often I feel sad and depressed.

28. I feel people forget how sick I am.

24. I feel it isn't serious enough to tell other people about it.

32. I'm very resentful.

12. I'm so lonely.

14. I feel totally dependent and helpless. 
CASE B: FACTOR II

Normalized

Factor

Score:

2. 02

1.82

1.55

1.30

1.29

1.22

1.10

1.07

0.98

0.86

0.63

0.46

0.41

0.40

0.16

0.09

$-0.08$

$-0.12$

$-0.20$

$-0.34$

$-0.41$

$-0.42$

$-0.46$

$-0.53$

$-0.65$

$-0.67$

$-0.70$

$-0.74$

$-0.91$

$-1.04$

$-1.10$

$-1.11$

$-1.14$

$-1.18$

$-1.65$

$-1.92$

\section{Item}

34. I feel nobody tells me what's going on.

5. Often I feel sad and depressed.

32. I'm very resentful.

29. I pray to be well.

16. I'd give anything to be well.

30. I have so little patience with people.

3. I feel I live under a shadow all the time.

12. I'm so lonely.

20. I think, not me, it can't be true.

15. I wouldn't care about anything else if my one wish could come true.

31. I feel there are new scientific discoveries every day.

22. I feel the doctors are still searching for the right treatment for me.

6. I feel some things must be finished.

13. I feel I have unfinished business.

17. I feel miracles do happen.

26. I feel people are overreacting to my illness.

23. I ask, Why did God let this happen to me?

19. I'm so tired of being sick I could scream.

7. I feel there's so much I have to get done.

27. I'm at peace with myself.

11. I feel there is a purpose in my illness.

1. I feel giving up old relationships is so painful.

10. I'm trying to buy extra time.

18. I'11 keep going as if nothing had happened.

9. I want my life to just quietly drift along.

26. I feel people forget how sick I am.

2. I'm just waiting.

8. I'm content with what my life has been.

35. I expect they' 11 soon discover new wayts to treat' my illness.

24. I feel it isn't serious enough to tell other people about it.

33. I've stopped doing anything.

4. I'm ready now for whatever happens.

14. I feel totally dependent and helpless.

25. I don't believe it.

21. Nothing bothers me anymore.

36. I'm busy planning for the future. 


\section{CASE B: FACTOR III}

Normalized

Factor

Score

2.07

1.84

1.48

1.35

1.17

0.92

0.91

0.75

0.73

0.68

0.55

0.45

0.43

0.41

0.34

0.20

0.11

0.10

0.06

0.06

$-0.10$

$-0.26$

$-0.31$

$-0.54$

$-0.55$

$-0.68$

$-0.69$

$-0.72$

$-0.77$

$-0.84$

$-0.85$

$-1.35$

$-1.36$

$-1.39$

$-2.06$

$-2.14$
Item

4. I'm ready now for whatever happens.

36. I'm busy planning for the future.

12. I'm so lonely.

7. I feel there's so much I have to get done.

22. I feel the doctors are still searching for the right treatment for me.

34. I feel nobody tells me what's going on.

11. I feel there is a purpose in my illness.

6. I feel some things must be finished.

8. I'm content with what my life has been.

24. I feel it isn't serious enough to tell other people about it.

29. I pray to be well.

14. I feel totally dependent and helpless.

3. I feel I live under a shadow all the time.

27. I'm at peace with myself.

35. I expect they' 11 soon discover new ways to treat my illness.

5. Often I feel sad and depressed.

15. I wouldn't care about anything else if my one wish could come true.

16. I'd give anything to be well.

28. I feel people forget how sick I am.

13. I feel I have unfinished business.

9. I want my life to just quietly drift along.

1. I feel giving up old relationships is so painful.

31. I feel there are new scientific discoveries every day.

21. Nothing bothers me anymore.

32. I'm very resentful.

10. I'm trying to buy extra time.

26. I feel people are overreacting to my illness.

17. I feel miracles do happen.

19. I'm so tired of being sick I could scream.

18. I'11 keep going as if nothing had happened.

30. I have so little patience with people.

25. I don't believe it.

2. I'm just waiting.

23. I ask, Why did God let this happen to me?

20. I think, not me, it can't be true.

33. I've stopped doing anything. 
LIST OF REFERENCES 
Achte, K. A., and Vouhkonen, M. L. Cancer and the psyche. Omega, 1971, $\underline{2}, 46-56$.

Cappon, D. The dying. Psychiatric Quarterly, 1959, 33, 466-489.

Carey, R. G. Emotional adjustment in terminal patients: a quantitative approach. Journal of Counseling Psychology, 1974, 21, 433-439.

Davies, R. K., Quinlan, D. M., McKegney, F. P., and Kimbal1, C. P. Organic factors and psychological adjustment in advanced cancer patients. Psychosomatic Medicine, 1973, 35, 464-471.

Dudley, D. L., Verhey, J. W., Masuda, M., Maston, C. J., and Holmes, T. H. Long-term adjustment, prognosis, and death in irreversible diffuse obstructive pulmonary syndromes. Psychosomatic Medicine, 1969, 31, 310-325.

Dukes, W. F. $\mathrm{N}=1$. Psychological Bulletin, 1965, 64, 74-79.

Feifel, H. (Ed.). The meaning of death. New York: McGraw-Hill, 1959.

Hertzberg, L. J. Cancer and the dying patient. American Journal of Psychiatry, 1972, 128, 806-810.

Hinton, J. M. The physical and mental distress of the dying. Quarterly Journal of Medicine, 1963, 32, 1-21.

Hinton, J. M. Dying (2nd ed.). Baltimore: Penguin Books, 1972.

Kastenbaum, R. The mental life of dying geriatric patients. Geronto1ogist, $1967, \underline{7}, 97-100$.

Kastenbaum, R., and Aisenberg, R. The psychology of death. New York: Springer, 1972.

Kastenbaum, R., and Weisman, A. D. The psychological autopsy as a research procedure in gerontology. In D. P. Kent, R. Kastenbaum, and S. Sherwood (Eds.), Research planning and action for the elderly. New York: Behavioral Publications, 1972.

Kubler-Ross, E. On death and dying. New York: Macmillan, 1969.

Lester, D. Experimental and correlational studies of the fear of death. Psychological Bulletin, 1967, 67, 27-36.

Lieberman, M. A. Psychological correlates of impending death: some preliminary observations. Journal of Gerontology, 1965, 20, 181-190.

Liberman, M. A. Observations on death and dying. Gerontologist, 1966, 6, 70-72. 
Lieberman, M. A., and Coplan, A. S. Distance from death as a variable in the study of aging. Developmental Psychology, 1970, 2 , 71-84.

Nunnally, J. C. An investigation of some propositions of selfconception: the case of Miss Sun. Journal of Abnormal and Social Psychology, 1955, 50, 87-92.

Nunnally, J. C. Psychometric theory. New York: McGraw-Hil1, 1967.

Schulz, R., and Aderman, D. Clinical research and the stages of dying. Omega , 1974, 5, 137-143.

Stephenson, W. The study of behavior: Q-technique and its methadology. Chicago: University of Chicago Press, 1953.

Subotnik, L. Transference in child therapy: a third replicatiom. Psychological Record, 1966, 16, 265-277.

Thomas, J. M., Jr., and Weiner, E. A. Psychological differences among groups of critically ill hospitalized patients, noncritically ill hospitalized patients, and well controls. Journal of Consulting and Clinical Psychology, 1974, 42, 274-279.

Wahl, C. W. The fear of death. Bulletin of the Menninger Clinic, 1958, $\underline{22}, 214-223$.

Zinker, J. C., and Fink, S. L. The possibility for psychological growth in a dying person. Journal of General Psychology, 1966, 74, 185-199. 